\title{
High-Temperature Behavior of Spent Li-Ion Battery Black Mass in Inert Atmosphere
}

\author{
Safoura Babanejad ${ }^{1}(1) \cdot$ Hesham Ahmed $^{1,2} \cdot$ Charlotte Andersson $^{1} \cdot$ Caisa Samuelsson ${ }^{1} \cdot$ Andreas Lennartsson $^{1}$. \\ Björn Hall ${ }^{3}$ Linn Arnerlöf ${ }^{4}$
}

Received: 15 September 2021 / Accepted: 7 February 2022 / Published online: 28 February 2022

(C) The Author(s) 2022

\begin{abstract}
The increased demand for Li-ion batteries has prompted the scientific community to improve recycling routes in order to reuse the valuable materials in batteries. After their end-of-life, the batteries are collected, discharged, and mechanically disintegrated, generating plastic and metallic streams that are recycled directly; this leaves behind a small particle size fraction known as black mass (BM). BM is composed mainly of graphite and Li-metal complex oxides. Pyrometallurgy is a route known for recycling of BM, in which identifying the BM's behavior at high temperatures is essential. In this study, two types of BM are characterized in two fractions of 150-700 $\mu \mathrm{m}$ and smaller than $150 \mu \mathrm{m}$. The thermal behavior of the BM is studied with thermal analysis techniques. The analyses demonstrate that the mineralogical and morphological properties of the two fractions do not significantly differ, while the amounts of $\mathrm{C}$ and organic materials might vary. When the BM was thermally treated, the binders decomposed until a temperature of $500{ }^{\circ} \mathrm{C}$ was reached, where the volatilization of hydrocarbons was observed, although $\mathrm{F}$ mostly persisted in the $\mathrm{BM}$. The Li-metal oxide was partially reduced to lower oxides and Li carbonate at $\sim 600{ }^{\circ} \mathrm{C}$, and the main mass loss was caused by carbothermic reduction immediately thereafter. As the products of this process, metallic $\mathrm{Co}$ and $\mathrm{Ni}$ phases were formed, and part of the graphite remained unreacted. Regarding the Li behavior, it was observed that in the presence of $\mathrm{Al}, \mathrm{AlLiO}_{2}$ is the most likely composition to form, and it changes to $\mathrm{LiF}$ by increasing the $\mathrm{F}$ concentration in the composition.
\end{abstract}

The contributing editor for this article was Zhi Sun.

Safoura Babanejad

safbab@1tu.se

1 Department of Civil, Environmental and Natural Resource Engineering, Process Metallurgy, Minerals and Metallurgical Engineering, Luleå University of Technology, 97187 Luleå, Sweden

2 Central Metallurgical Research and Development Institute, P.O. Box 87, Helwan 114 21, Egypt

3 Stena Recycling International AB, P.O. Box 4088, 40040 Gothenburg, Sweden

4 Boliden Smelters, Klarabergsviadukten 90 A, Stockholm, Sweden 


\section{Graphical Abstract}

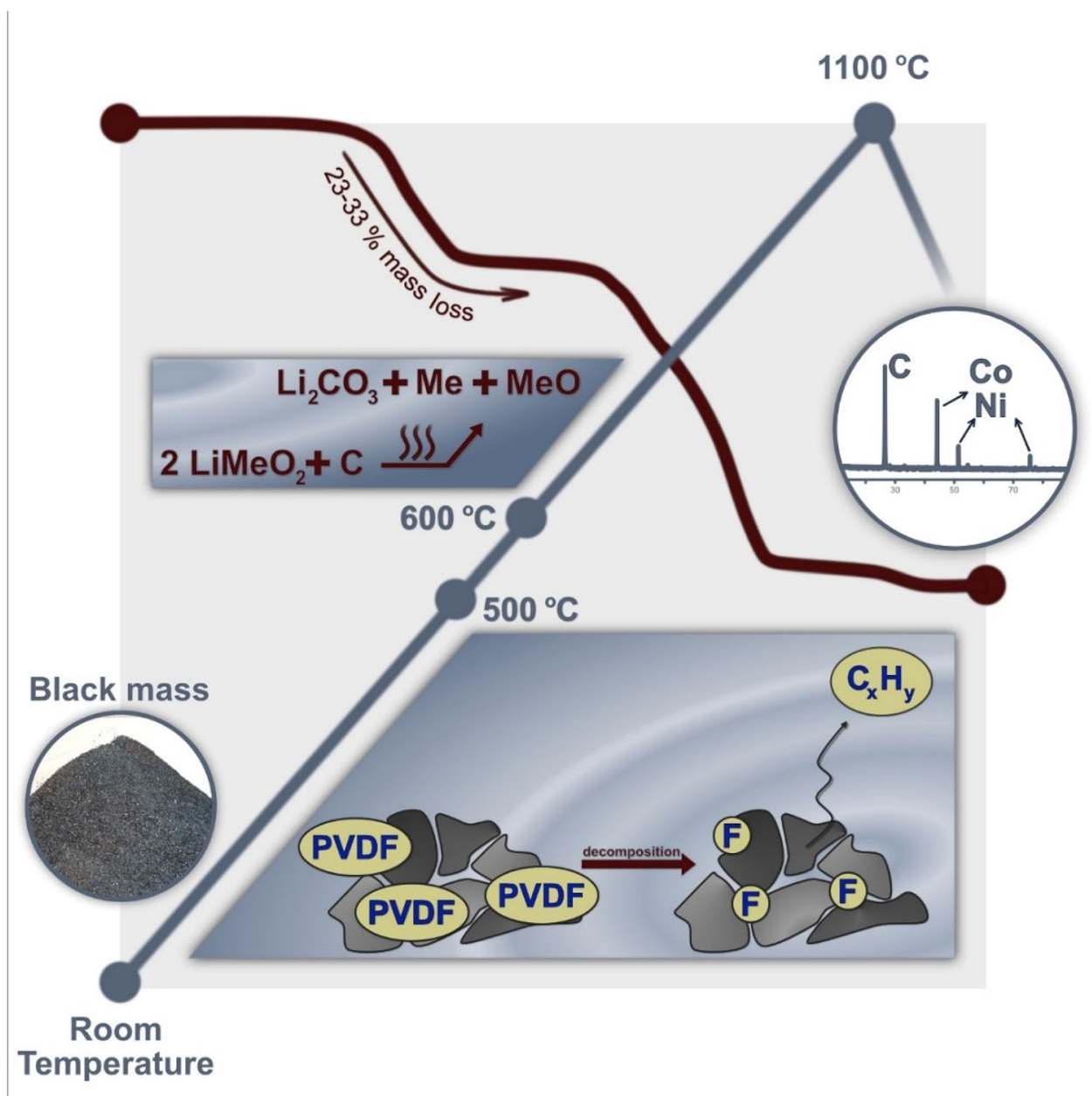

Keywords Li-ion battery black mass $\cdot$ Recycling $\cdot$ Pyrometallurgy $\cdot$ Thermal analysis $\cdot$ Fluorine

\section{Introduction}

Since the beginning of the 1990s, Li-ion batteries (LIBs) have been regarded as the most promising energy storage solution for various applications due to their high energy density, low memory effect, low self-discharge, and long lifespan. Due to the increasing demand in fossil-free energy, a large amount of LIBs is produced today. It is predicted that the number of electric vehicles will increase from 4 million in 2018 to 900 million in 2048 [1-4]. By 2025, it is expected that $\sim 850,000$ tons of LIBs will need to be recycled globally. In the regulatory proposal concerning batteries and waste batteries published by the European Commission, special attention should be given to recycling of end-of-life (EOL) batteries and closing the material loops. The regulation states that the recycling efficiency of LIBs should exceed $65 \%$ by 2025 [5]. The use of eco-friendly and resource-efficient methods for handling LIB components after EOL relieves environmental contamination pressure, generates remarkable economic and social benefits, and reduces the dependency on primary materials $[6,7]$.

After their EOL, LIBs are mechanically collected, discharged, and disintegrated. This generates plastic and metallic streams, which can be recycled directly by physical separation, leaving behind a small particle size fraction, known as black mass (BM) $[8,9]$. The BM contains anode materials (mainly graphite), cathode materials (e.g., $\mathrm{LiMeO}_{2}$ ), binders (usually polyvinylidene fluoride (PVDF)), conductive additives (acetylene black), traces of electrolyte (typically Li salt dissolved in an organic solvent), and electrode current collector residuals $(\mathrm{Cu}$ and $\mathrm{Al})[1,10,11]$.

The process for recycling of BM typically starts with a pretreatment process, to liberate the battery components, and enhance the efficiency of target elements recovery. 
According to the literature, thermal pretreatment at 500-600 ${ }^{\circ} \mathrm{C}$ can be used to evaporate organic materials in BM (e.g., electrolyte, separator, and PVDF residuals) that contain F, which is known as a hazardous and corrosive element [10, 12-14]. Chemical and thermal procedures can be employed separately to remove binders and facilitate BM particle separation. Flotation, which is a physical pretreatment method, is used to separate the graphite particles in the BM based on their wettability properties $[10,15]$. Pyro- and hydrometallurgical processes, as the main methods for extracting metals, usually follow the pretreatment step. In pyrometallurgy, valuable metals are recovered at high temperatures based on their physical and chemical properties [4], while in hydrometallurgy, the process of metal recovery is performed based on aqueous chemistry at low temperatures, in which a combination of different techniques, e.g., leaching, solvent extraction, and precipitation, are performed [16-20]. These two major methods have pros and cons, such as the emission of hazardous gas in pyrometallurgy and the production of wastewater in hydrometallurgy processes. The higher efficiency of the hydrometallurgical routes makes them more popular for the recycling of LIBs. This effect stands out in particular in the recovery of $\mathrm{Li}$, of which most is lost in the slag in almost all commercial pyrometallurgical processes, such as Umicore and Inmetco. However, in hydrometallurgical recycling processes, LIB pretreatment, such as passivation, is often a prerequisite to facilitate processes like leaching [9]. The main advantage of the pyrometallurgical methods is their industrial simplicity, e.g., the technology is currently ready, and there is no obligation to apply passivation steps $[9-11,17]$. The use of pyrometallurgical methods, under efficient conditions, would be an easier option for the recycling of LIBs. To develop such a method, the initial stage is to determine the high-temperature properties and behavior of the material-in this case, BM. There are various battery types that generates different BM compositions. In this regard, some studies have been performed to investigate the effect of high-temperature treatment on different battery compositions both on the cathode/anode active material, a mix of them, or unaltered BM.

In 2019, Wang et al. roasted the cathodes of LCO batteries (cathode material: $\mathrm{LiCoO}_{2}$-anode material: graphite) that consisted of $\mathrm{Al}$ foil, PVDF, acetylene black, and $\mathrm{LiCoO}_{2}$. Roasting was performed under an Ar atmosphere, where the formation of $\mathrm{Li}_{2} \mathrm{O}, \mathrm{AlLiO}_{2}$, and $\mathrm{CoO}$ plus incomplete degradation of PVDF was observed after reaching a temperature of $600{ }^{\circ} \mathrm{C}$. This study revealed that $\mathrm{Al}$ acts as the primary reductant of $\mathrm{LiCoO}_{2}$ to $\mathrm{CoO}$ [21]. Lombardo et al. showed that pyrolysis of BM from NMC batteries (cathode material: $\mathrm{LiNi}_{x} \mathrm{Mn}_{y} \mathrm{Co}_{z} \mathrm{O}_{2}$-anode material: graphite) at 600 and $700{ }^{\circ} \mathrm{C}$ completely decomposed the cathode active material via a carbothermic reaction to its constituents, including $\mathrm{Co}, \mathrm{Ni}$, and $\mathrm{Mn}_{3} \mathrm{O}_{4}$, and $\mathrm{Al}$ remained unreacted. In analyzing the released gas from the samples, no F-containing compounds were detected [22]. Incineration of these batteries was also investigated by these authors, where $\mathrm{F}$ was detected in the gaseous products and byproducts after thermal treatment [23]. Kwon and Sohn studied the thermokinetics of $\mathrm{LiCoO}_{2}$ and graphite up to $1500{ }^{\circ} \mathrm{C}$ in an $\mathrm{Ar}$ atmosphere and reported a temperature range of $880-1200{ }^{\circ} \mathrm{C}$ as the optimal temperature for the recovery of $\mathrm{Li}$ and $\mathrm{Co}$. They stated that part of $\mathrm{LiCoO}_{2}$ is reduced to $\mathrm{Co}_{3} \mathrm{O}_{4}$ at $500{ }^{\circ} \mathrm{C}$ and that the total transformation to $\mathrm{CoO}$ and $\mathrm{Li}_{2} \mathrm{CO}_{3}$ occurs at 607-689 ${ }^{\circ} \mathrm{C}$. $\mathrm{Li}_{2} \mathrm{CO}_{3}$ decomposes to $\mathrm{Li}_{2} \mathrm{O}$ and $\mathrm{CO}_{2}$ at $689-882{ }^{\circ} \mathrm{C}$, and $\mathrm{Co}$ forms as the product of $\mathrm{CoO}$ reduction at $882-1128{ }^{\circ} \mathrm{C}$. The mass loss at higher temperatures was assigned to the Boudouard reaction toward producing CO in this study [24]. The literature mentions that heating the LFP cathode material $\left(\mathrm{LiFePO}_{4}\right)$ at $450-650{ }^{\circ} \mathrm{C}$ would remove PVDF (up to $96.85 \mathrm{wt} \%)$, in which the $\mathrm{F}$ content decreases from $8.51 \mathrm{wt} \%$ (before pyrolysis) to $1.67 \%$ (collected oil after pyrolysis). In this study, the decrease in $\mathrm{F}$ content was attributed to the evaporation of HF [13].

To develop a sustainable pyrometallurgical method that enables efficient BM recycling, a thorough understanding of its behavior at high temperatures is needed. In terms of cathode material decomposition, there are some contradictory comprehensions of the reactions that occur, and the following work aims to clarify these reactions. Moreover, an element of importance at high temperature is $\mathrm{F}$ and its behavior, which is poorly understood. Special attention is devoted to this aspect in the current work, mainly by tracking $\mathrm{F}$ in the solid-state. In this study, two types of BM obtained from commercial spent LIBs via mechanical separation routes were characterized with focus on their thermal behavior.

\section{Experimental}

\section{Materials}

The BM from the following two types of LIBs were considered in this study: LCO batteries from portable mobile phones and NMC batteries from car batteries $\left(\mathrm{LiNi}_{0.33} \mathrm{Mn}_{0.33} \mathrm{Co}_{0.33} \mathrm{O}_{2}\right.$ as the cathode active material in this study). The as-received BM samples were produced, mechanically separated, and heat treated at $250-300{ }^{\circ} \mathrm{C}$ (to remove the electrolyte) by Stena Recycling International $\mathrm{AB}$, Sweden. The samples were in two particle size ranges: particles smaller than $150 \mu \mathrm{m}$ and particles between 150 and $700 \mu \mathrm{m}$.

To more deeply investigate the $\mathrm{LiCoO}_{2}$ transformation, $\mathrm{LiCoO}_{2}(99.8 \%$, Aldrich) together with graphite $(-300$ mesh, 99\%, Alfa Aesar, and APS 7-11 micron, 99\%, Alfa Aesar), Al (+325 mesh, 99.5\%, Alfa Aesar), and PVDF (HSV 900, Arkema) were used to investigate the effect of 
some elements, i.e., $\mathrm{C}, \mathrm{Al}$, and $\mathrm{F}$, in the $\mathrm{BM}$ on the decomposition of $\mathrm{LiCoO}_{2}$.

\section{Characterization}

A variety of methods were employed to chemically, mineralogically, and morphologically characterize BM at both room and high temperatures. For chemical analysis, inductively coupled plasma-mass spectrometry (ICP-MS) was used to analyze most of the elements. The procedure was performed according to SS EN ISO 17294-2:2016 and EPA method 200.8:1994. In addition, measurement of the $C$ content was conducted by combustion analysis using a LECO CS230. The ion selective electrode (ISE) method was utilized to analyze the amount of $\mathrm{F}$ in the samples, applying EPA method 9214. To employ this method in analyzing the solid samples, $0.5 \mathrm{~g}$ of the sample was mixed with $\sim 2 \mathrm{~g} \mathrm{Na}_{2} \mathrm{O}_{2}$ in a Ni crucible and covered with $\sim 1 \mathrm{~g} \mathrm{Na}_{2} \mathrm{O}_{2}$. The mixture was subsequently melted at $800{ }^{\circ} \mathrm{C}$ for $8 \mathrm{~min}$ and after cooling in room temperature for $10 \mathrm{~min}, 20 \mathrm{~mL}$ of deionized water was added to entirely dissolve the solid sample. The solution was thereafter adjusted to $1000 \mathrm{~mL}$ with the addition of deionized water. $20 \mathrm{~mL}$ of the new solution was transferred to another beaker and the $\mathrm{pH}$ of the solution was regulated to neutral with acetic acid using phenolphthalein as an indicator, and then $20 \mathrm{~mL}$ of TISAB buffer solution was added. The titration was performed using a Metrohm 888 Titrando.

Mineralogical characterization was performed by particle size distribution (PSD) (Retsch Camsizer XT) and X-ray diffraction (XRD). A PANalytical Empyrean X-ray diffractometer in $\theta-\theta$ geometry with $\mathrm{Cu}-\mathrm{K} \alpha$ radiation $(\lambda=0.154184 \mathrm{~nm})$, a beam current of $40 \mathrm{~mA}$, and a beam voltage of $45 \mathrm{kV}$ was used for the measurement. The XRD pattern was measured in the $2 \theta$ range of $20^{\circ}-90^{\circ}$ with a step size of $0.026^{\circ} / \mathrm{s}$. A curved graphite crystal monochromator mounted in front of a PIXcel 3D detector was used to remove the fluorescence due to the presence of Fe in the samples. The measured data were evaluated for phase identification using HighScore Plus (v4.7, PANalytical B.V., Almelo, The Netherlands) software, and FIZ-NIST Inorganic Crystal Structure Database (ICSD) and Crystallography Open Database (COD) databases. The morphology of the as-received BM samples was investigated under a Zeiss Merlin field emission gun scanning electron microscope (SEM) equipped with an Oxford Instruments
X-Max energy dispersive X-ray spectroscopy (EDS) detector with AZtec software.

\section{Thermal Analysis}

To detect the high-temperature behavior of BM in a reductive atmosphere, a Netzsch STA 409 instrument with a detection limit of $1 \mu \mathrm{g}$ was utilized to conduct thermogravimetric/differential thermal analysis (TGA/DTA) under an $\mathrm{Ar}$ atmosphere (flow rate of $100 \mathrm{~mL} / \mathrm{min}$ ) and with a heating rate of $10{ }^{\circ} \mathrm{C} / \mathrm{min}$. The gases that evolved during the experiments were continuously monitored using a quadrupole mass spectrometer (QMS) for qualitative analysis.

Additionally, the phases that developed upon heating were identified by the same XRD instrument used for the mineralogical characterization, which was equipped with an Anton Paar HTK $1200 \mathrm{~N}$ high-temperature chamber that was used to heat the sample to $1000{ }^{\circ} \mathrm{C}$ at a heating rate of $10{ }^{\circ} \mathrm{C} /$ min and He flow rate of $10 \mathrm{~mL} / \mathrm{min}$. To analyze the sample at the desired temperature, the sample was held at the set temperature for $1 \mathrm{~min}$ before acquiring the XRD pattern, which was measured in the $2 \theta$ range of $15^{\circ}-65^{\circ}$ with a step size of $0.083^{\circ} \mathrm{s}$.

\section{$\mathrm{LiCoO}_{2}$ Reduction}

The transformation of LCO BM to its components was simulated by the synthetic materials as listed in Table 1. The proportions were set based on the LCO BM composition. The heating trial, which was applied to the LCO BM, was repeated in these experiments to perform TGA/DTA. For the last experiment with $\mathrm{LCO}+\mathrm{Gr}+\mathrm{Al}+\mathrm{PVDF}$, the graphite that was used had the particle size of 7-11 $\mu \mathrm{m}$.

\section{F Behavior}

To monitor whether $\mathrm{F}$ evaporates during heating in the pretreatment step, the BM was analyzed by the ISE method on the following occasions: (i) before heating at 250-300 ${ }^{\circ} \mathrm{C}$ (see "Materials" section); (ii) the as-received BM; (iii) $\mathrm{BM}$ after pyrolysis at $700{ }^{\circ} \mathrm{C}$ in an $\mathrm{Ar}$ atmosphere for $1 \mathrm{~h}$; and (iv) $\mathrm{BM}$ after incineration at $700{ }^{\circ} \mathrm{C}$ (in a synthetic air atmosphere) for $1 \mathrm{~h}$.
Table 1 Chemical composition used in the complementary experiments

\begin{tabular}{|c|c|c|c|c|c|c|c|c|}
\hline \multirow[t]{2}{*}{ Sample } & \multicolumn{4}{|l|}{$(\mathrm{g})$} & \multicolumn{4}{|l|}{$(w t \%)$} \\
\hline & $\mathrm{LiCoO}_{2}$ & Graphite & $\mathrm{Al}$ & PVDF & $\mathrm{LiCoO}_{2}$ & Graphite & $\mathrm{Al}$ & PVDF \\
\hline LCO & 55.9 & - & - & - & 100.0 & - & - & - \\
\hline $\mathrm{LCO}+\mathrm{Gr}$ & 55.9 & 35.4 & - & - & 61.2 & 38.8 & - & - \\
\hline $\mathrm{LCO}+\mathrm{Gr}+\mathrm{Al}$ & 55.9 & 35.4 & 0.9 & - & 60.6 & 38.4 & 1.0 & - \\
\hline $\mathrm{LCO}+\mathrm{Gr}+\mathrm{Al}+\mathrm{PVDF}$ & 55.9 & 35.4 & 0.9 & 4.42 & 57.9 & 36.6 & 0.9 & 4.6 \\
\hline
\end{tabular}




\section{Thermodynamic Modeling}

To identify the reaction mechanisms and evaluate/support the experimental results, a set of calculations using the Equilib module in the thermodynamic software FactSage 8.0 were conducted [25]. The FactPS and FToxid databases were used in the present calculations. When using FactSage, the low-concentration elements were omitted. The FToxidSLAGA, FToxid-SPINA, FToxid-MeO_A, FToxid-NAShB, and FToxid-NASIB solution phases were selected together with the ideal gas phase and pure solids species. To simulate the synthetic air atmosphere, the $\mathrm{O}_{2}$ activity was set to 0.2 .

\section{Results and Discussion}

\section{Chemical Analysis}

The chemical compositions of both BM types in the coarse and fine fractions are listed in Table 2. The data reveal that for the LCO BM, the composition of the fine and coarse fractions is approximately the same. In addition to $\mathrm{Li}, \mathrm{Co}$, and $\mathrm{C}$, some traces of $\mathrm{Al}, \mathrm{Cu}, \mathrm{P}$, and $\mathrm{F}$ are detected. In contrast, a difference in the compositions of the two fractions is observed for the NMC BM. The main difference is the amount of $\mathrm{C}$, which is much higher in the coarse fraction, while there is a lower amount of the other main elementse.g., $\mathrm{Li}, \mathrm{Co}$, and $\mathrm{Ni}$. The amounts of the other elements are approximately the same in both fractions.

The Li-to-Co ratio in the LCO case (both fractions) is the same as the Li-to-Co ratio in $\mathrm{LiCoO}_{2}$, the cathode material in the $\mathrm{LCO}$ batteries. In the NMC BM, the ratio between the $\mathrm{Li}, \mathrm{Co}, \mathrm{Ni}$, and $\mathrm{Mn}$ amounts is equivalent to the $\mathrm{LiNi}_{0.33} \mathrm{Mn}_{0.33} \mathrm{Co}_{0.33} \mathrm{O}_{2}$ phase. The high amount of $\mathrm{C}$ in the compositions of both types of $\mathrm{BM}$ is attributed to the graphite in the anode. In the NMC case, the $\mathrm{C}$ content is much higher in the coarse fraction, leading to a lower proportion of cathode material ( $\mathrm{Li}, \mathrm{Co}, \mathrm{Ni}$, and $\mathrm{Mn}$ ). In other words, for NMC, $\mathrm{C}$ accumulates in the coarse fraction, while the $\mathrm{LiNi}_{0.33} \mathrm{Mn}_{0.33} \mathrm{Co}_{0.33} \mathrm{O}_{2}$ ratio in the fine fraction is higher. The $\mathrm{Al}$ and $\mathrm{Cu}$ traces likely originate from current collector residuals in the BM. Si and P are from the additive materials in the anode, and $\mathrm{F}$ is the corrosive element that exists mainly in PVDF, but there are also some other F sources, such as electrolyte and anode additives $[17,26]$.

\section{Mineralogical and Morphological Investigation}

The PSD results of the LCO BM show $\mathrm{d} 10$, d50, and $\mathrm{d} 90$ values of $0.02,0.06$, and $0.14 \mathrm{~mm}$ in the fine fraction and $0.15,0.31$, and $0.71 \mathrm{~mm}$ in the coarse fraction, respectively. In the NMC BM, the results were $<0.01,0.04$, and $0.13 \mathrm{~mm}$ for $\mathrm{d} 10, \mathrm{~d} 50$, and $\mathrm{d} 90$ in the fine fraction, and $0.15,0.34$, and $0.71 \mathrm{~mm}$ in the coarse fraction, respectively. The analysis indicates that in each fraction, the $\mathrm{d} 10, \mathrm{~d} 50$, and $\mathrm{d} 90$ values are almost equal in the LCO and NMC BM. The main difference might stem from the $\mathrm{d} 10$ of the fine fractions, which has a much smaller particle size in the NMC BM.

XRD measurements were conducted on the two fractions of LCO and NMC BM provided. The XRD data obtained from the LCO BM (Fig. 1a) reveal that the active cathode material is mainly $\mathrm{LiCoO}_{2}$ and that the anode material primarily consists of graphite (shown as $\mathrm{Gr}$ in the figures). $\mathrm{LiNi}_{0.33} \mathrm{Mn}_{0.33} \mathrm{Co}_{0.33} \mathrm{O}_{2}$ (denoted by $\mathrm{NMC}^{*}$ in the figures) is the primary active cathode material detected in the NMC $\mathrm{BM}$ (Fig. 1b). The XRD results from the different fractions (coarse and fine) are similar in terms of the phase types, while they exhibit a slight difference in the intensity of detected peaks in the BM fractions.

As shown in Fig. 2, the SEM images from the as-received LCO BM show irregular and sheet-like particles in a wide size range. The SEM images also show that larger particles are actually agglomerates of smaller particles. The agglomeration could be caused by the residual binder or could be connected to the material's physical properties (size and surface). EDS analyses show that the sheet-like particles mainly consisted of $\mathrm{C}$ ( $\mathrm{a} 1$ and $\mathrm{b} 3$ spectra), while the other types of particles were rich in $\mathrm{Co}(\mathrm{a} 2, \mathrm{a} 3, \mathrm{~b} 1$, and b2). $\mathrm{Li}$ was not detectable by EDS but based on XRD data it can be assumed that the particles rich in Co could represent the $\mathrm{LiCoO}_{2}$ phase.

The SEM images of the BM samples from NMC batteries (Fig. 3) show a large number of small spheres in the range of $\sim$ 3-7 $\mu \mathrm{m}$. Higher magnification revealed that each sphere
Table 2 Chemical compositions of LCO and NMC BM in two fractions of $<150$ and $150-700 \mu \mathrm{m}$ (wt\%)

\begin{tabular}{lcccccccccc}
\hline Sample $(\mathrm{wt} \%)$ & $\mathrm{Li}$ & $\mathrm{Co}$ & $\mathrm{Ni}$ & $\mathrm{Mn}$ & $\mathrm{Al}$ & $\mathrm{Cu}$ & $\mathrm{Si}$ & $\mathrm{P}$ & $\mathrm{F}$ & $\mathrm{C}$ \\
\hline $\begin{array}{l}\mathrm{LCO} \\
<150 \mu \mathrm{m}\end{array}$ & 3.8 & 31.4 & 0.0 & 0.0 & 0.4 & 0.4 & 1.6 & 0.4 & 2.1 & 43.8 \\
$\begin{array}{l}\mathrm{LCO} \\
150-700 \mu \mathrm{m}\end{array}$ & 4.0 & 32.3 & 0.0 & 0.0 & 0.9 & 0.6 & 1.6 & 0.5 & 2.6 & 35.4 \\
$\mathrm{NMC}$ & & & & & & & & & & \\
$<150 \mu \mathrm{m}$ & 6.3 & 17.3 & 15.5 & 15.1 & 0.0 & 0.8 & 1.3 & 0.4 & 4.9 & 12.8 \\
$\begin{array}{l}\mathrm{NMC} \\
150-700 \mu \mathrm{m}\end{array}$ & 3.6 & 8.0 & 7.3 & 7.6 & 0.2 & 1.6 & 1.0 & 0.6 & 6.5 & 43.2 \\
\hline
\end{tabular}



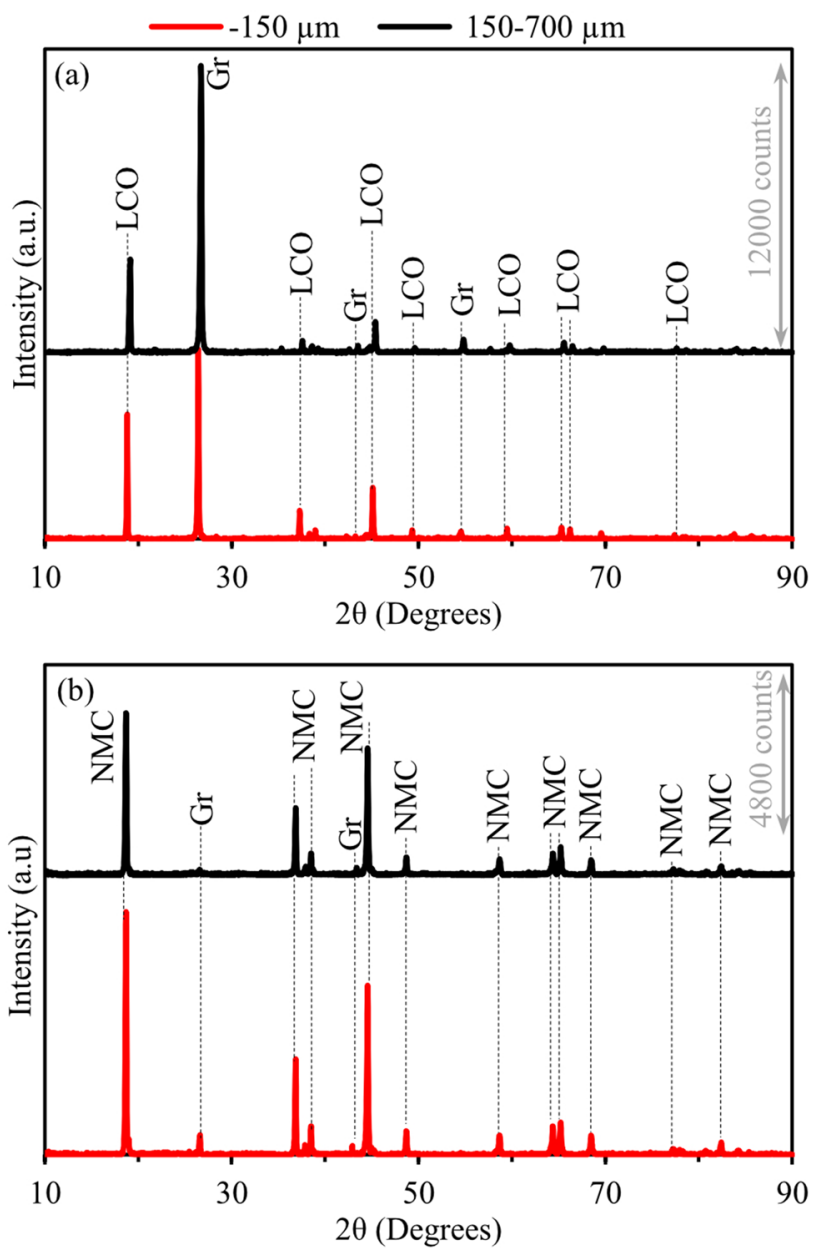

Fig. 1 XRD pattern of $\mathbf{a}$ LCO and $\mathbf{b}$ NMC BM

were comprised of much smaller particles ( 22 and a3). This assembly possibly originated from the cathode materials as these particles are rich in cathode material elements, i.e., Co, $\mathrm{Ni}$, and $\mathrm{Mn}$. A similar cathode composition is also observed in b1 and b4 in the NMC coarse fraction (see Fig. 3). Irregularly shaped particles were found in all samples with a wide range of sizes from a few microns up to a $100 \mu \mathrm{m}$ or slightly more. The small particles were aggregated into irregular agglomerates with a size range of several hundred microns. According to the EDS results, the matrix is rich in C, e.g., $\mathrm{a} 1, \mathrm{~b} 2$, and $\mathrm{b} 3$. In addition, $\mathrm{F}$ was detected with EDS both in LCO and NMC (Fig. 2 and Fig. 3) supporting the results from the chemical analysis showing the presence of F-containing compounds (e.g., PVDF) in the as-received BM.
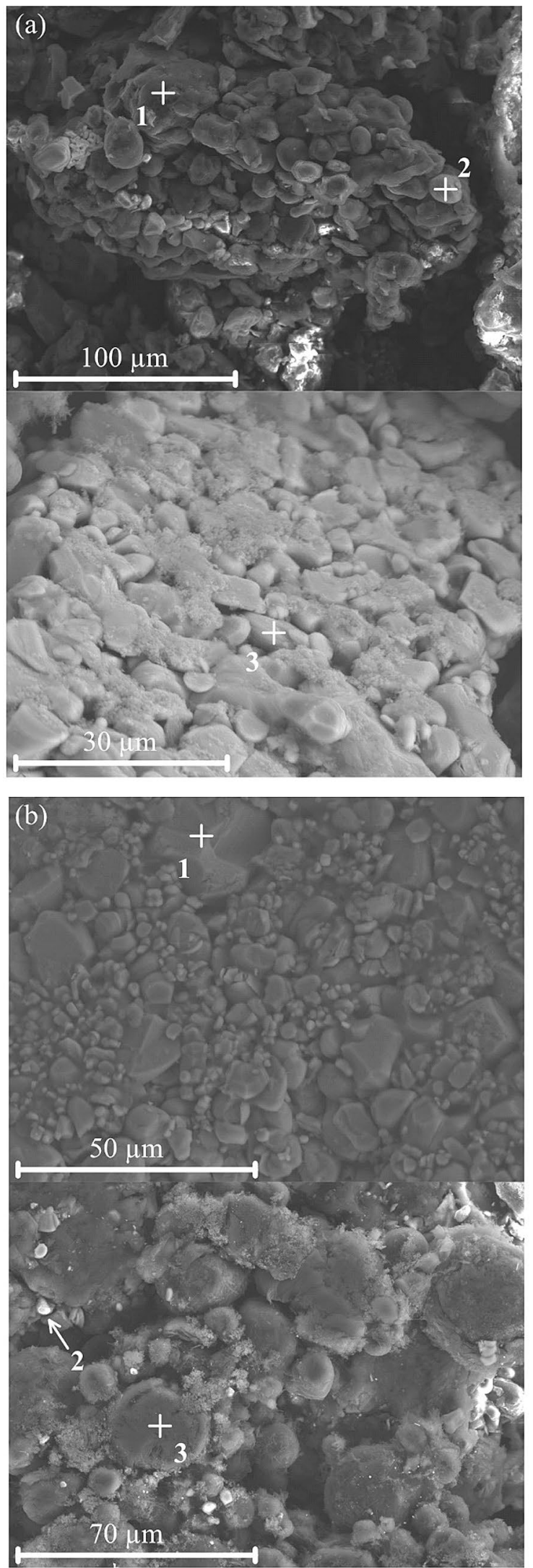

Fig. 2 SEM(SE)-EDS images of two fractions of the as-received LCO BM: $\mathbf{a}<150 \mu \mathrm{m}$ and $\mathbf{b} 150-700 \mu \mathrm{m}$ 

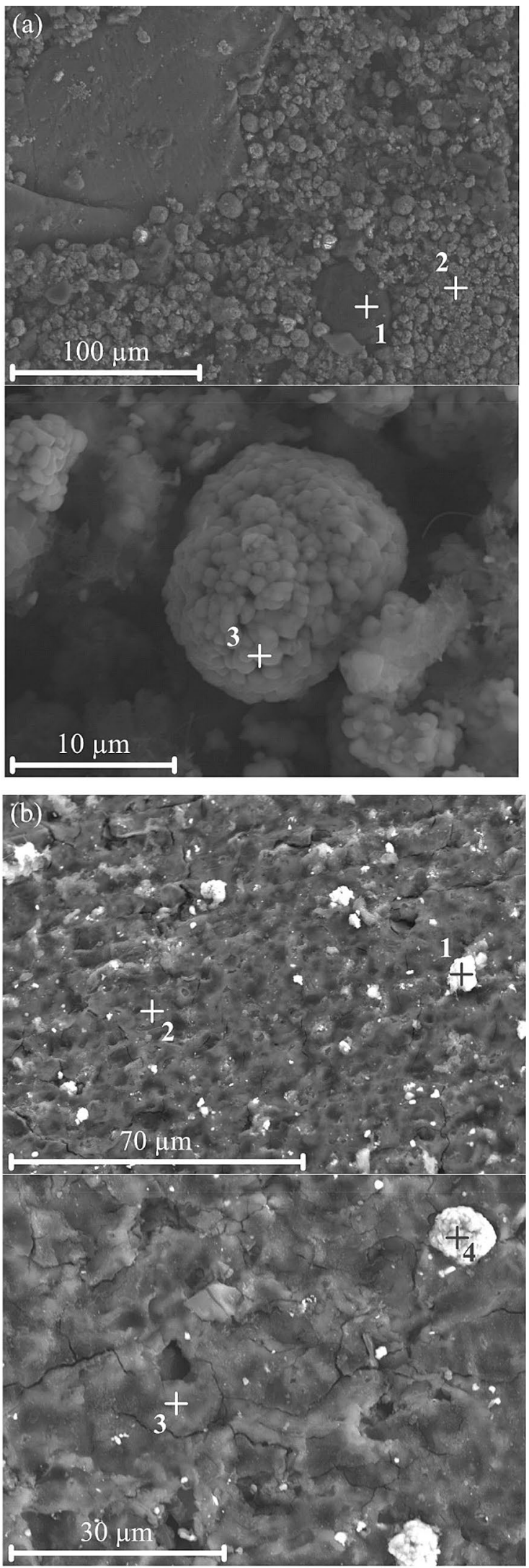

Fig. 3 SEM(SE)-EDS images of two fractions of the as-received NMC BM: $\mathbf{a}<150 \mu \mathrm{m}$ and $\mathbf{b} 150-700 \mu \mathrm{m}$

\section{Thermal Analysis}

\section{BM from LCO Batteries}

The TGA, DTA, and QMS results of the BM from LCO batteries are plotted in Fig. 4. To explain the behavior during heating, the heating profile was divided into three sections according to the mass loss slope and the occurring reactions. In section I, the mass loss, in the fine fraction, begins at $\sim 200-300{ }^{\circ} \mathrm{C}$ and continues until $5 \mathrm{wt} \%$ of the original mass is lost, while in the coarse fraction, it continues even further to approximately $10 \mathrm{wt} \%$ mass loss. Section I is associated with the production of hydrocarbons $\left(\mathrm{C}_{x} \mathrm{H}_{y}\right)$, together with $\mathrm{H}_{2} \mathrm{O}$ and $\mathrm{CO}_{2}$, as depicted in the QMS graph. In the middle of this section, a breakpoint (for both fractions) is observed, which synchronizes with a slight bump in the DTA graph that is even more apparent in the coarse fraction. Section I is followed by a gentle slope in section II, where an exothermic reaction takes place at $\sim 600{ }^{\circ} \mathrm{C}$. This reaction is not accompanied by any mass loss at that temperature, while sharp peaks of $\mathrm{H}_{2} \mathrm{O}$ and $\mathrm{CO}_{2}$ arise immediately thereafter (at slightly higher temperature) which synchronizes with a steeper slope in section III and continues until $\sim 900{ }^{\circ} \mathrm{C}$. The main mass loss, which is approximately $15-20 \mathrm{wt} \%$, occurs in section III. At $\sim 900{ }^{\circ} \mathrm{C}$, an endothermic peak appears in the DTA graph accompanied by a $\mathrm{CO}_{2}$ peak in the QMS graph.

In Fig. 5, XRD patterns obtained before and after reduction are shown. The as-received LCO BM mainly consists of $\mathrm{LiCoO}_{2}$ and graphite, while the main phases in the reduced BM were Co and graphite. High-temperature XRD was also conducted to better comprehend the exo/endothermic reactions noticed in the DTA graphs (Fig. 6). Similar to the as-received LCO BM in Fig. 5, the pattern at $25^{\circ} \mathrm{C}$ shows $\mathrm{LiCoO}_{2}$ and graphite as the main phases, along with the less intense peaks of $\mathrm{SiO}_{2}$ and $\mathrm{Al}_{2} \mathrm{O}_{3}$. When increasing the temperature to $550{ }^{\circ} \mathrm{C}, \mathrm{CoO}$ peaks arise, and when a temperature of $700{ }^{\circ} \mathrm{C}$ is reached the $\mathrm{LiCoO}_{2}$ peaks disappear entirely and $\mathrm{AlLiO}_{2}$ and Co phases appear. At $800{ }^{\circ} \mathrm{C}$, all $\mathrm{CoO}$ peaks disappear. When a temperature of $1000{ }^{\circ} \mathrm{C}$ is reached, a shift to the left in the peaks can be observed, an affect that could be attributed to lattice parameter changes by increasing temperature $[27,28]$. After cooling the LCO $\mathrm{BM}$ from $1000{ }^{\circ} \mathrm{C}$, graphite, $\mathrm{Co}, \mathrm{SiO}_{2}$, and $\mathrm{AlLiO}_{2}$ are the peaks recognized in the XRD pattern.

The TGA curves in Fig. $4 \mathrm{~b}$ show that the mass reduction of the coarse fraction is slightly higher than that of the fine fraction (Fig. 4a). Even so, the thermal behaviors of the two fractions are almost similar in the two fractions; subsequently, the following explanations apply to both (fine and coarse LCO BM).

The chemical composition (Table 2) gives an indication that the amount of $\mathrm{LiCoO}_{2}$ is the same in the fine and coarse 
(a)

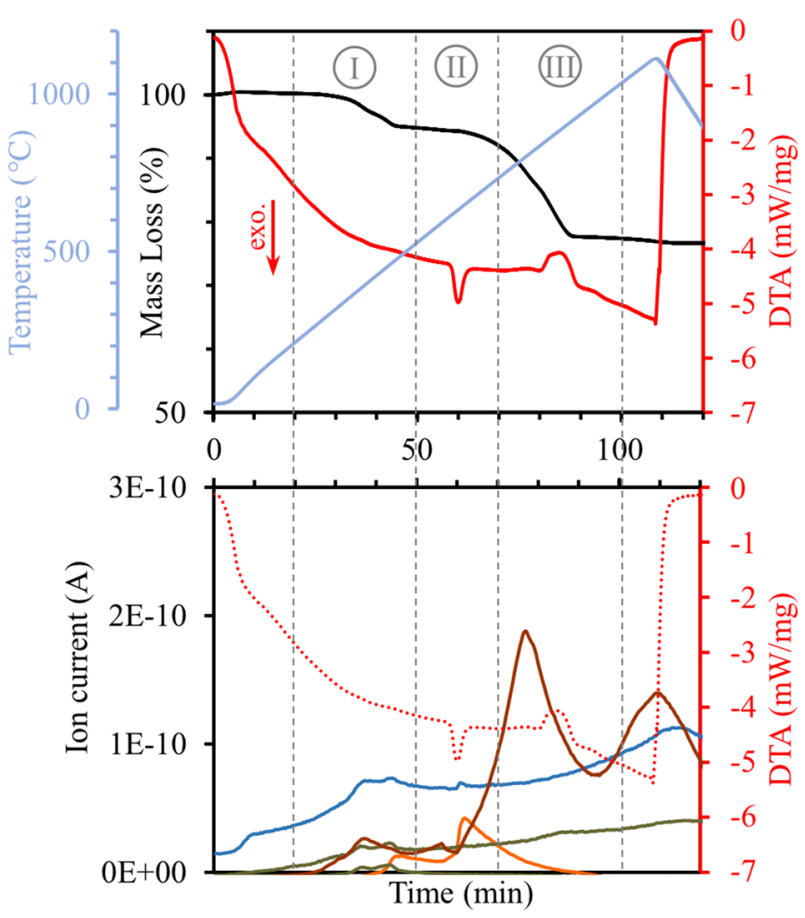

(b)

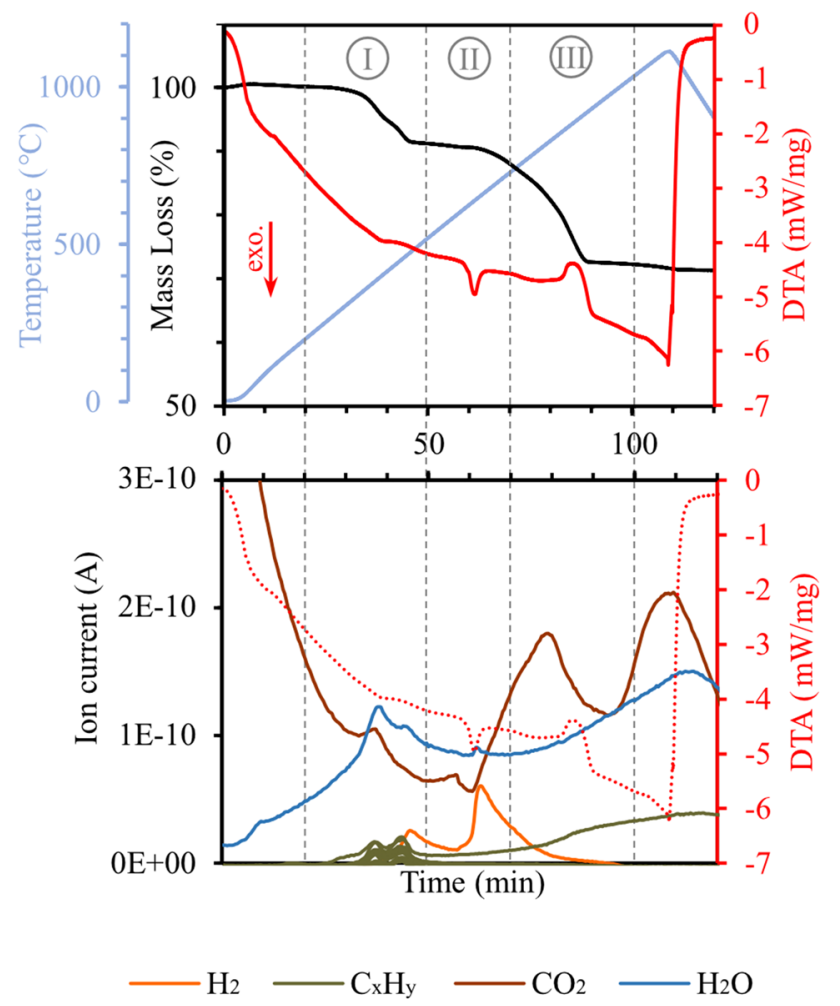

Fig. 4 TGA/DTA/QMS graphs of two fractions of the LCO BM: $\mathbf{a}<150 \mu \mathrm{m}$ and $\mathbf{b} 150-700 \mu \mathrm{m}$

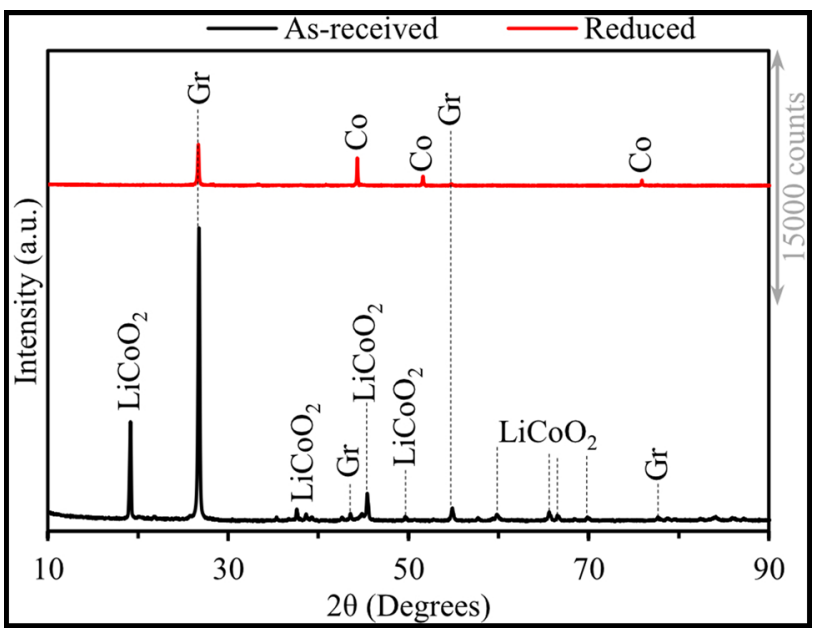

Fig. 5 XRD patterns of LCO BM before and after heat treatment at $1100{ }^{\circ} \mathrm{C}$

fractions of LCO BM, while more $\mathrm{C}$ was present in the fine fraction. Moreover, the XRD results (Fig. 5) demonstrate that graphite remains in the reduced coarse fraction, which has a lower amount of $\mathrm{C}$. This implies that more $\mathrm{C}$ was present than what was needed to ultimately reduce $\mathrm{LiCoO}_{2}$. In conclusion, more $\mathrm{C}$ in the fine fraction would result in more remaining $\mathrm{C}$ after the reduction and finally a lower total mass reduction.

In Fig. 4 section $\mathrm{I}$, the evolved gases $\left(\mathrm{C}_{x} \mathrm{H}_{y}, \mathrm{CO}_{2}\right.$, and $\mathrm{H}_{2} \mathrm{O}$ ) indicate dissociation or decomposition of an organic compound, which could be the binder and/or residual solvents. PVDF, as a binder, is spread on the particles to maintain a bond between the cathode/anode active material, current collectors, and acetylene black [29, 30]. With the decomposition of PVDF, it is possible for the acetylene black to oxidize. Since compared to graphite, acetylene black oxidizes at a lower temperature [31], the breakpoint in the TGA curve (section I) can be addressed to the reduction reaction of LCO in the presence of acetylene black. This reaction reduces the cathode active material metals from a higher oxidation state to a lower oxidation state [32], followed by the formation of $\mathrm{H}_{2} \mathrm{O}$ and $\mathrm{CO}_{2}$ in the QMS results. This can also be verified by the high-temperature XRD patterns (Fig. 6), where $\mathrm{CoO}$ peaks appear at $550{ }^{\circ} \mathrm{C}$ while $\mathrm{LiCoO}_{2}$ is still present. This implies that $\mathrm{LiCoO}_{2}$ has been partially altered to its components.

Figure 4 section II shows a plateau in the mass loss curve and an exothermic peak at approximately $600{ }^{\circ} \mathrm{C}$ in the DTA graph. The XRD patterns at 550 and $700{ }^{\circ} \mathrm{C}$ (Fig. 6) are literally measured before and after this reaction. Given these patterns, $\mathrm{LiCoO}_{2}$ has totally transformed to its components, of which one is $\mathrm{CoO}$, and according to the QMS data $\mathrm{CO}_{2}$ and $\mathrm{H}_{2} \mathrm{O}$ also release. Consequently, the exothermic reaction at $\sim 600{ }^{\circ} \mathrm{C}$ (Fig. 4) can be interpreted as a $\mathrm{LiCoO}_{2}$ 


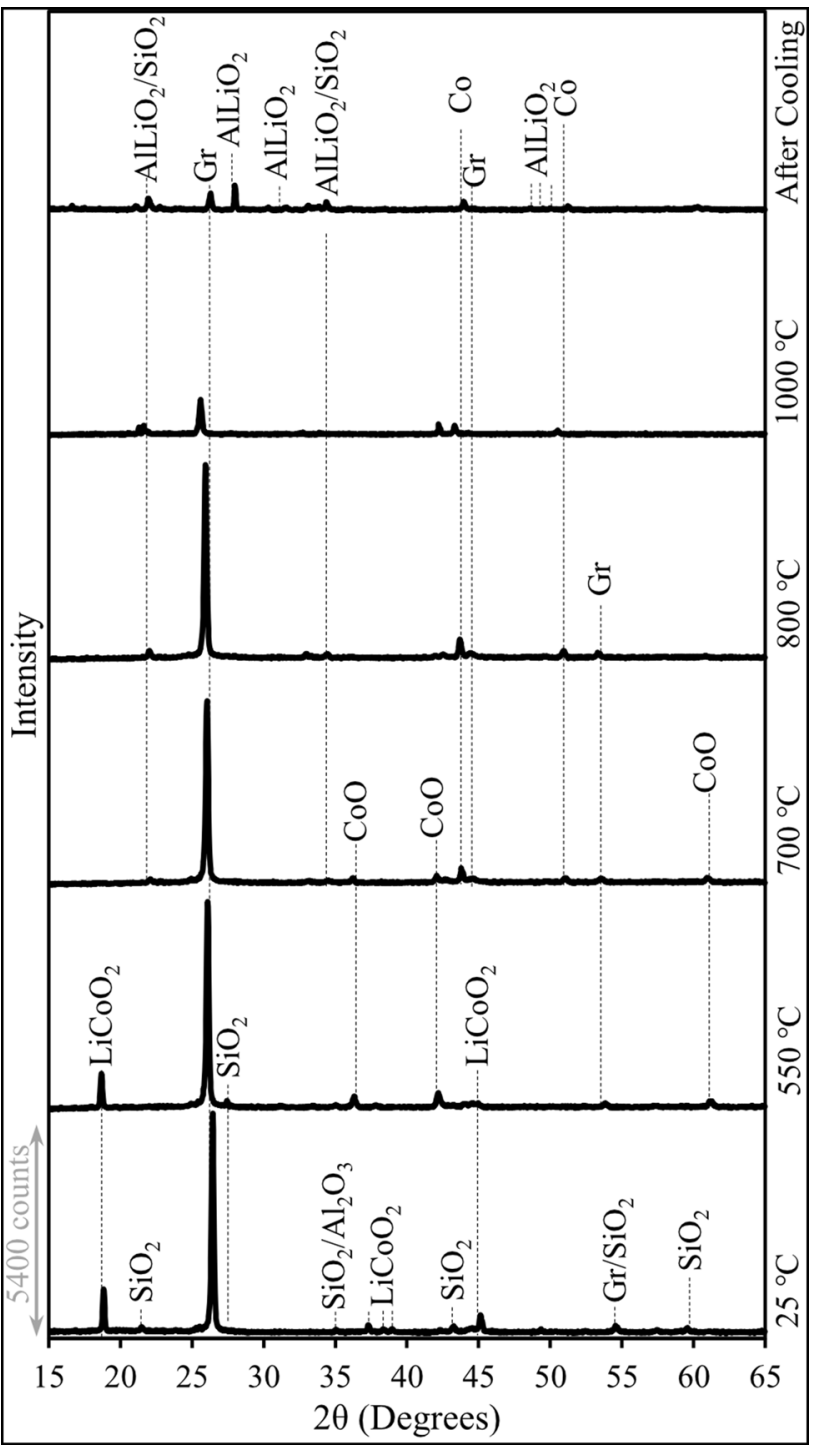

Fig. 6 XRD patterns during heating of the LCO BM to a temperature of $1000{ }^{\circ} \mathrm{C}$

transformation to simpler components. In addition, an $\mathrm{H}_{2}$ peak is observed in the QMS data that can be interpreted as the product of the secondary devolatilization of organic materials/binder or residual plastics [33]. The diffractogram at $700{ }^{\circ} \mathrm{C}$ shows the beginning of $\mathrm{CoO}$ reduction where a Co phase forms.

To determine the nature of this reaction, chemical-grade $\mathrm{LiCoO}_{2}$ reduction trials were performed as explained in the Experimental " $\mathrm{LiCoO}_{2}$ Reduction" section. The results are plotted in Fig. 7. It should be mentioned that the temperature difference $\left(\sim 40{ }^{\circ} \mathrm{C}\right)$ of the exothermic reaction in the $\mathrm{LCO}+\mathrm{Gr}+\mathrm{Al}+\mathrm{PVDF}$ sample is due to the smaller graphite particle size, which improves the kinetics of the reaction.

First of all, $\mathrm{LiCoO}_{2}$ was placed in an inert atmosphere and heated to $1100{ }^{\circ} \mathrm{C}$ and the figure shows that it did not decompose until the temperature reached almost $1100{ }^{\circ} \mathrm{C}$; however, when graphite was added, the decomposition began at a much lower temperature $\left(630-670{ }^{\circ} \mathrm{C}\right)$. The same scenario is observed by the addition of $\mathrm{Al}$ and PVDF. The DTA graphs show that an exothermic reaction occurs at 630-670 ${ }^{\circ} \mathrm{C}$. The notable point is that the TGA graph shows no mass loss, implying that the reduction has not started at this point. S. Kuzuhara et al. (2020) reported that this exothermic reaction can be due to Eq. 1, which has no accompanying mass loss and is thermodynamically feasible at temperatures higher than $488{ }^{\circ} \mathrm{C}$ [34].

$2 \mathrm{LiCoO}_{2}+\mathrm{C} \rightarrow \mathrm{Li}_{2} \mathrm{CO}_{3}+\mathrm{Co}+\mathrm{CoO}$

Increasing the temperature to $\sim 680{ }^{\circ} \mathrm{C}$, the mass loss begins. It can be concluded that the reaction occurring at 630-670 ${ }^{\circ} \mathrm{C}$ (Eq. 1) facilitates reduction at higher temperatures $\left(680^{\circ} \mathrm{C}\right)$. It is worth mentioning that the difference in reaction temperature between the synthetic $\mathrm{LiCoO}_{2}$ mixture and LCO BM may be related to kinetic reasons such as the surface area and size of particles. The $\mathrm{LiCoO}_{2}$ phase transformation is followed by the main mass loss. Considering Fig. 6 with the high-temperature XRD patterns (Fig. 6), it can be concluded that the reduction of Co oxides to metallic Co begins after the $\mathrm{LiCoO}_{2}$ phase transformation.

The endothermic peak observed at $\sim 800{ }^{\circ} \mathrm{C}$ is synchronized with a slope change in the mass loss. This reaction can be addressed to the decomposition of $\mathrm{Li}_{2} \mathrm{CO}_{3}$ to $\mathrm{Li}_{2} \mathrm{O}$ and $\mathrm{CO}_{2}$. This reaction can also be expected in the LCO BM, where $\mathrm{CO}_{2}$ peaks are rising at this temperature (Fig. 4); however, $\mathrm{Li}_{2} \mathrm{CO}_{3}$ peaks were not detected by high-temperature XRD (Fig. 6). This may be because during LCO BM reduction, $\mathrm{Li}_{2} \mathrm{CO}_{3}$ forms at a temperature that is close to its melting point $\left(733{ }^{\circ} \mathrm{C}[35]\right)$. Accordingly, the loss of the crystal structure at that temperature range might be the reason that $\mathrm{Li}_{2} \mathrm{CO}_{3}$ peaks are not identified in the XRD pattern.

The endothermic reaction detected at $\sim 900{ }^{\circ} \mathrm{C}$ is attributed to the gasification of $\mathrm{C}$ (Boudouard reaction) [14] or $\mathrm{Li}_{2} \mathrm{O}$ volatilization [21]. According to the FactSage calculations performed in this study, the emitted gas phase has a very low content of $\mathrm{Li}_{2} \mathrm{O}$, while the $\mathrm{CO}_{2}$ peak after this reaction can be seen in the QMS graphs (Fig. 4). Hence, the gasification of $\mathrm{C}$ seems to be more feasible.

Total mass loss values of $\sim 23$ and $\sim 29 \mathrm{wt} \%$ were observed in the case of fine and coarse fractions, respectively. To conclude, heating the LCO BM to $1100{ }^{\circ} \mathrm{C}$ in an inert atmosphere results in the production of $\mathrm{Co}$ as a metallic part, leaving behind excess unreacted graphite.

The equilibrium was calculated with FactSage (Fig. 8), which shows that the most abundant stable phases at $1100{ }^{\circ} \mathrm{C}$ would be the $\mathrm{Co}(\mathrm{s})$, graphite, and gas phases. The slag phase (referred to liquid/glass solution in FactSage) would mainly consists of $\mathrm{Li}_{2} \mathrm{O}$, which was not detected by XRD. $\mathrm{AlLiO}_{2}$, 
Fig. 7 TGA/DTA graphs of three different chemical-grade LCO compositions heated to $1100{ }^{\circ} \mathrm{C}$
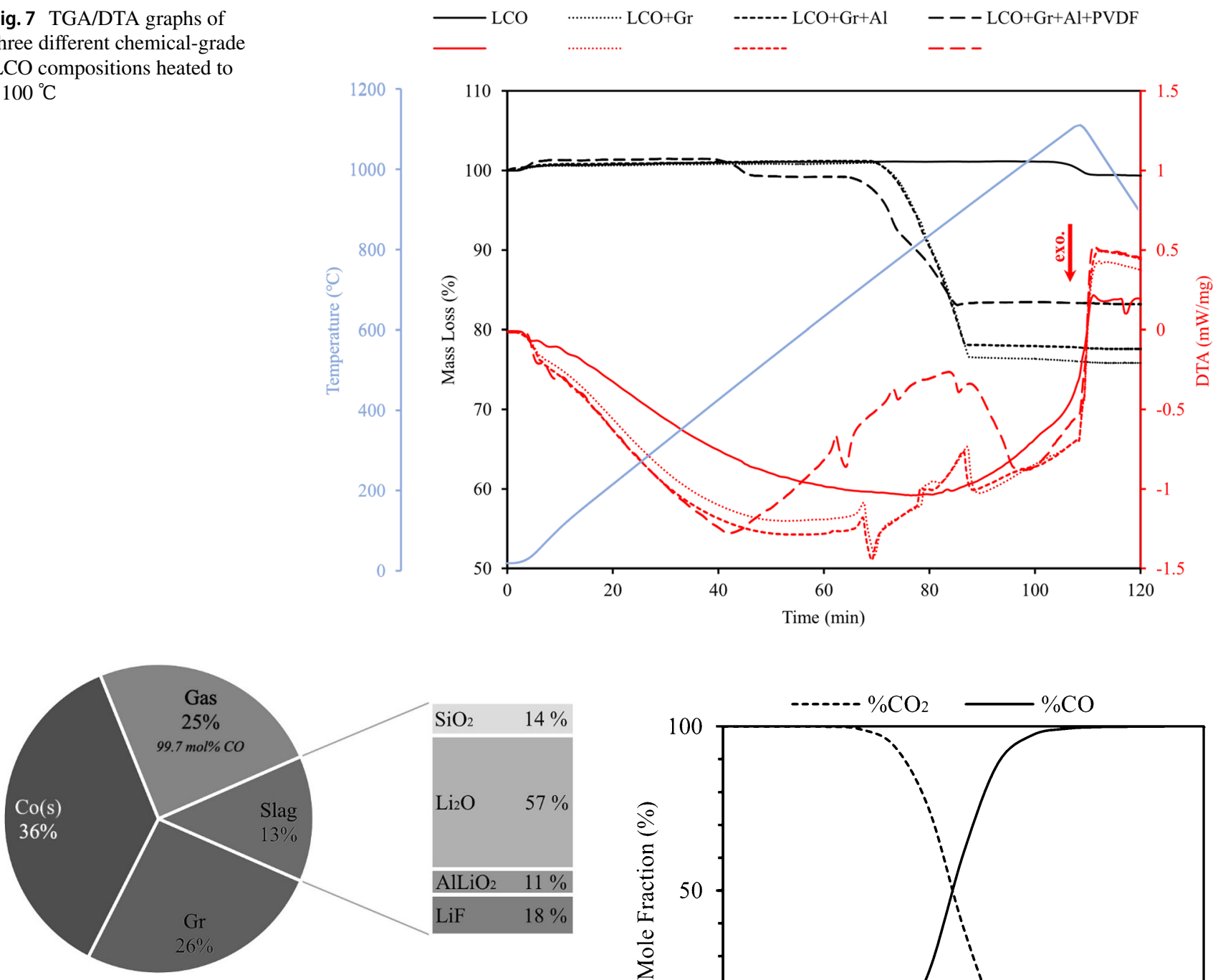

Fig. 8 LCO BM heat treated at $1100{ }^{\circ} \mathrm{C}$, calculated by FactSage: Phase distribution and the slag calculated components

$\mathrm{LiF}$, and $\mathrm{SiO}_{2}$ are also thermodynamically probable at this temperature. The thermodynamically estimated behavior of BM upon heating in an inert atmosphere is in line with the experimental results, except for Li-containing compounds. It seems that the $\mathrm{Al}$ content in the high-temperature XRD sample was higher than the average chemical composition, which made the $\mathrm{AlLiO}_{2}$ the abundant Li-containing phase during heating. This difference might be due to the inhomogeneity of BM that commonly contains large current collector particles ( $\mathrm{Al}$ and $\mathrm{Cu}$ ), which might change the local chemical composition and make it difficult to obtain a representative sample.

To calculate the mass reduction by theoretical stoichiometry equations, the amount of $\mathrm{O}$ in the LCO BM should be considered. Theoretically, $32.7 \mathrm{wt} \% \mathrm{O}$ exists in the $\mathrm{LiCoO}_{2}$. To eliminate $\mathrm{O}$, the $\mathrm{C}$ amount needed depends on the gas produced, i.e., $\mathrm{CO}$ or $\mathrm{CO}_{2}$, which can be studied by the

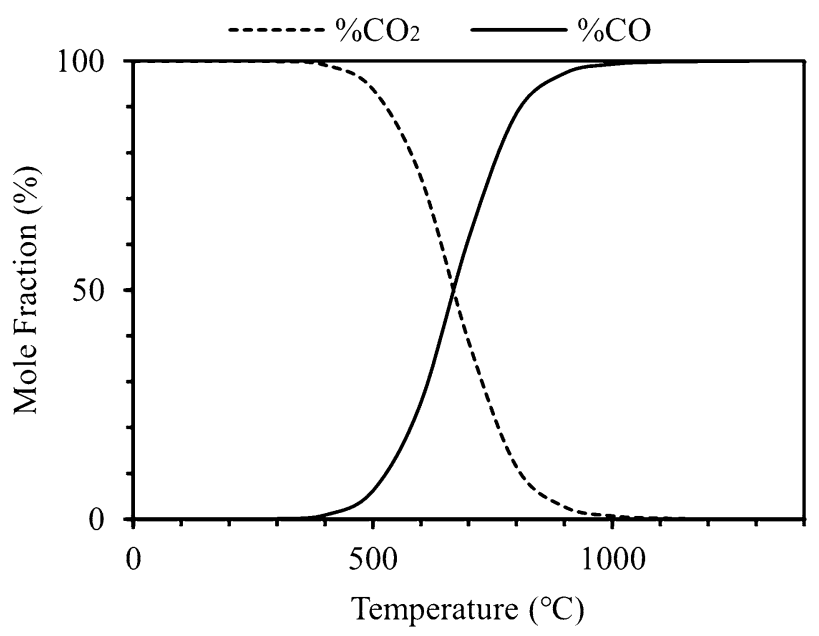

Fig. 9 Equilibrium mole fraction of $\mathrm{CO}$ and $\mathrm{CO}_{2}$ with $\mathrm{C}$ based on the Boudouard reaction

Boudouard reaction (Fig. 9). Therefore, it can be deduced that the $\mathrm{CO}: \mathrm{CO}_{2}$ ratio in the temperature range of $\mathrm{LCO} \mathrm{BM}$ carbothermic reactions $\left(600-900{ }^{\circ} \mathrm{C}\right)$ is approximately $3: 1$.

The total reduction of the cathode material by graphite (as the main reductant in the $\mathrm{BM}$ ), considering the thermodynamics calculations, can be simplified to Eq. 2. In this case, the mass loss was $\sim 23 \mathrm{wt} \%$, which agrees with the total mass loss in the TGA curves. It is worth mentioning that in comparing the theoretical and experimental results, the mass loss ratio should be calculated after reaching a temperature of $500{ }^{\circ} \mathrm{C}$ because the mass loss before that is related to PVDF decomposition, which is not included in Eq. 2. 
$\mathrm{LiCoO}_{2}+1.2 \mathrm{C} \rightarrow 0.5 \mathrm{Li}_{2} \mathrm{O}+\mathrm{Co}+0.9 \mathrm{CO}+0.3 \mathrm{CO}_{2}$

\section{BM from NMC Batteries}

Figure 10 depicts the TGA, DTA, and QMS results from the NMC BM during heating. Similar to the LCO BM, the mass loss trend has been divided into the following three sections: the mass loss begins in section I, slope plateaus form in section II, and section III begins with a steeper slope. Prior to section I and at its beginning, $\mathrm{C}_{x} \mathrm{H}_{y}$ peaks arise at $\sim 300{ }^{\circ} \mathrm{C}$ most likely attributed to the decomposition of PVDF. Fine and coarse fractions of NMC BM show four exothermic reactions at $\sim 300, \sim 400, \sim 600$, and $\sim 800{ }^{\circ} \mathrm{C}$. The two latter reactions are followed by intense $\mathrm{CO}_{2}$ and $\mathrm{H}_{2} \mathrm{O}$ peaks in the QMS graphs.

The XRD patterns of the NMC BM before and after heating are illustrated in Fig. 11. The main phases in the asreceived $\mathrm{BM}$ are $\mathrm{LiNi}_{0.33} \mathrm{Mn}_{0.33} \mathrm{Co}_{0.33} \mathrm{O}_{2}$ and graphite with a weak peak. The intensity of the graphite peak does not match the $\mathrm{C}$ content analyzed by combustion analysis. Hence, part of the $\mathrm{C}$ amount can be accounted for by acetylene black, whose main XRD peak is in the same $2 \theta$ as graphite, while, compared to graphite, its main peak is weak and broad [36]. This assumption will be discussed later in this section. The XRD pattern indicates that $\mathrm{LiF}$ and metallic $\mathrm{Co}$ and $\mathrm{Ni}$ are formed in addition to graphite after reduction.

The high-temperature XRD patterns in this case (Fig. 12) include a broad hump that is more discernible at room temperature and disappears gradually with increasing temperature. This bump might be related to an amorphous phase such as PVDF [22]. The phases detected at $25^{\circ} \mathrm{C}$ were previously identified (Fig. 11) in the as-received BM XRD pattern (Fig. 11). There were also $\mathrm{Cu}$ peaks originating from the current collector residuals in the $\mathrm{BM}$. At $550{ }^{\circ} \mathrm{C}, \mathrm{SiO}_{2}$ was identified alongside $\mathrm{LiNi}_{0.33} \mathrm{Mn}_{0.33} \mathrm{Co}_{0.33} \mathrm{O}_{2}$, graphite, and $\mathrm{Cu}$. At $700{ }^{\circ} \mathrm{C}$, the $\mathrm{Co} / \mathrm{Ni}$ and $\mathrm{MnO}$ peaks replaced the $\mathrm{LiNi}_{0.33} \mathrm{Mn}_{0.33} \mathrm{Co}_{0.33} \mathrm{O}_{2}$ peaks. The pattern remained almost constant at 900 and $1000{ }^{\circ} \mathrm{C}$. After cooling from $1000{ }^{\circ} \mathrm{C}$ to room temperature, the final phases can be summarized as $\mathrm{SiO}_{2}, \mathrm{Co} / \mathrm{Ni}$, graphite, $\mathrm{MnO}, \mathrm{LiF}$, and $\mathrm{Cu}$.

Unlike the BM from LCO, the NMC BM fractions showed significant variations in their compositions with fractionation (Table 2). This difference is distinguishable in the mass loss curves in Fig. 10, where the coarse fraction with the higher amount of $\mathrm{C}$ has a lower total mass reduction. The limited amount of reducible oxygen can explain the lower mass loss in the coarse fraction compared to the fine fraction. The total mass loss amounts were found to be $\sim 33$ and $\sim 25 \mathrm{wt} \%$ for the fine and coarse fractions, respectively. The same TGA trend as for the LCO BM is observed in section I of the TGA curve for NMC BM, where PVDF decomposition $\left(\sim 300{ }^{\circ} \mathrm{C}\right)$ and acetylene black oxidation (a)

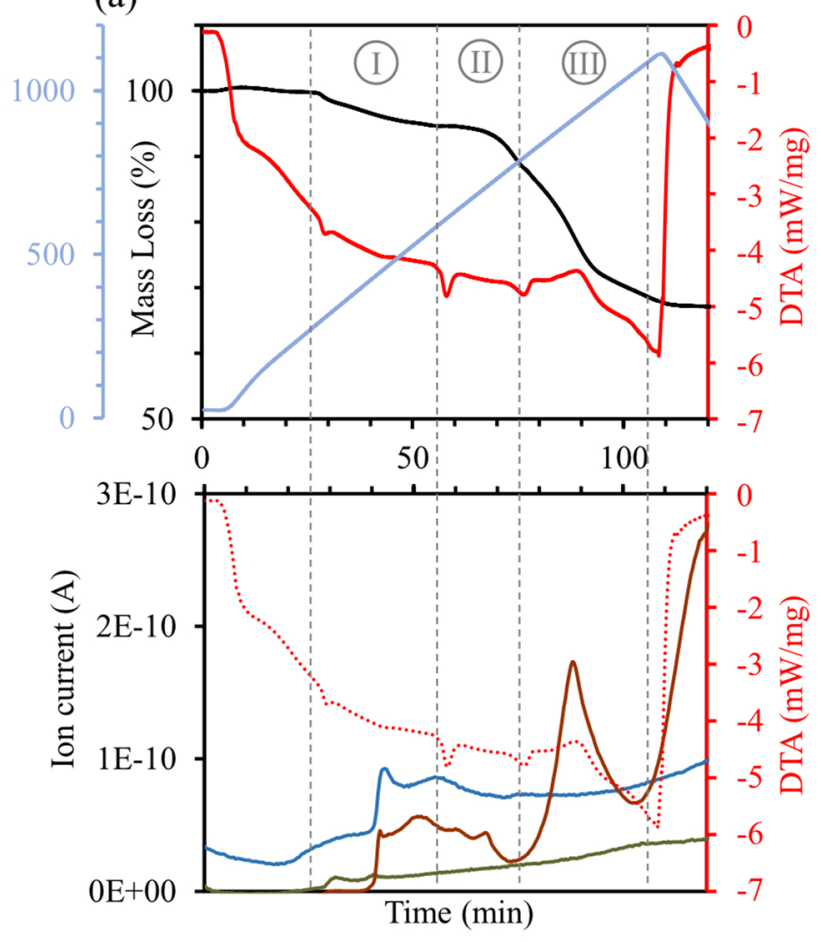

(b)
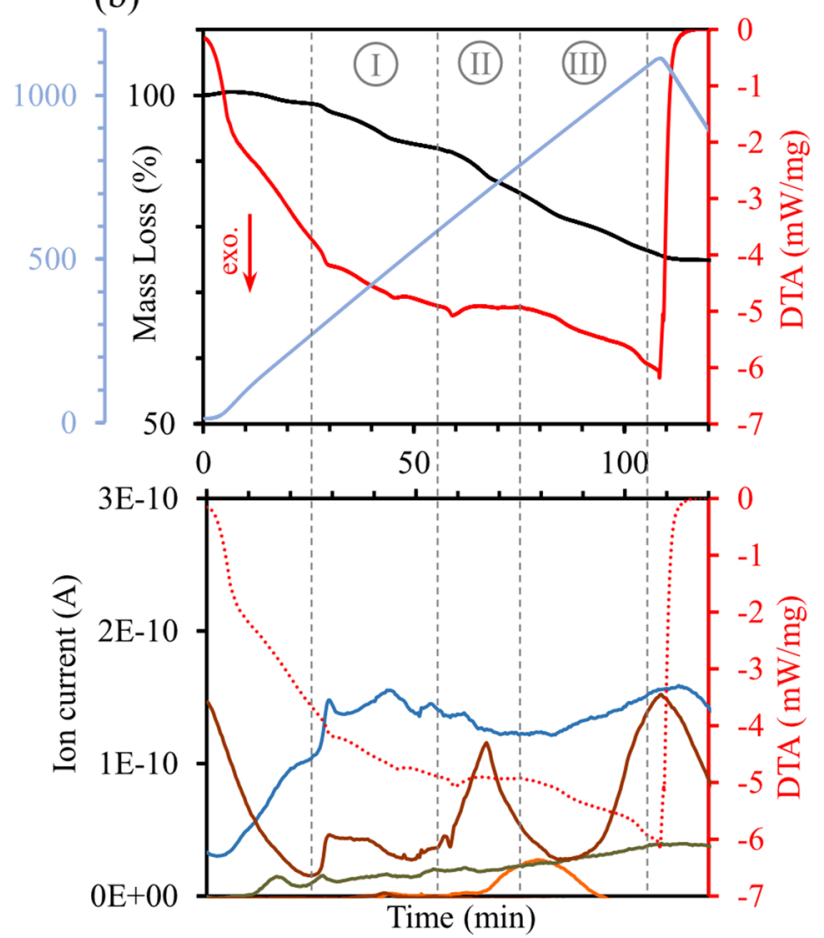

$-\mathrm{H}_{2}-\mathrm{C}_{\mathrm{x}} \mathrm{H}_{\mathrm{y}}-\mathrm{CO}_{2}-\mathrm{H}_{2} \mathrm{O}$

Fig. 10 TGA/DTA/QMS graphs of two fractions of the NMC BM: $\mathbf{a}<150 \mu \mathrm{m}$ and $\mathbf{b} 150-700 \mu \mathrm{m}$ 


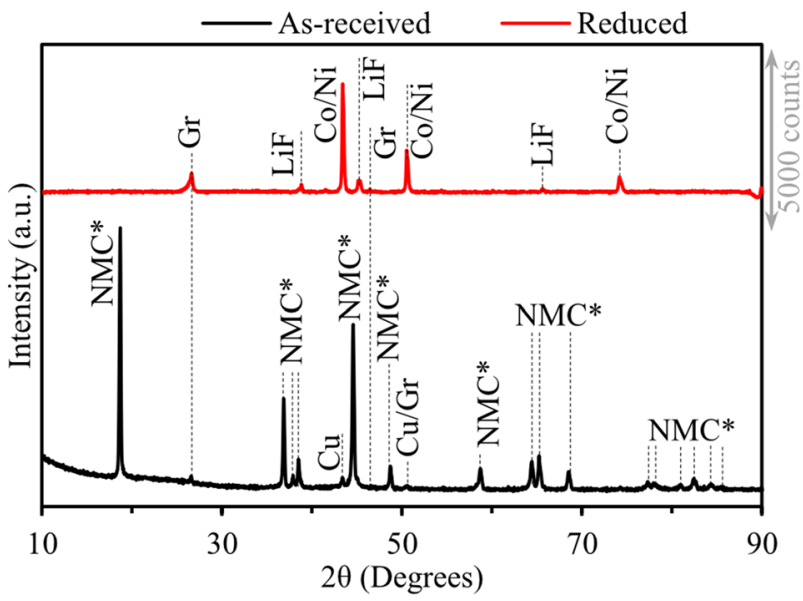

Fig. $11 \mathrm{XRD}$ patterns of NMC BM before and after heat treatment at $1100{ }^{\circ} \mathrm{C}$

$\left(\sim 400{ }^{\circ} \mathrm{C}\right.$ ) occurred. The mass loss in section II continues with a different slope, and QMS peaks corresponding to $\mathrm{CO}_{2}$ and $\mathrm{H}_{2} \mathrm{O}$ are observed immediately after the exothermic reaction at $\sim 600{ }^{\circ} \mathrm{C}$ (Fig. 10). The XRD patterns at 550 and $700{ }^{\circ} \mathrm{C}$ in Fig. 12 show that $\mathrm{LiNi}_{0.33} \mathrm{Mn}_{0.33} \mathrm{Co}_{0.33} \mathrm{O}_{2}$ transformed to metallic $\mathrm{Co}$ and $\mathrm{Ni}$ and $\mathrm{MnO}$ in that temperature interval. Accordingly, at $\sim 600{ }^{\circ} \mathrm{C}$, the transformation of $\mathrm{LiNi}_{0.33} \mathrm{Mn}_{0.33} \mathrm{Co}_{0.33} \mathrm{O}_{2}$ in the $\mathrm{BM}$ occurs, which has also been reported by Vishvakarma and Dhawan [14]. Unlike in the LCO BM, mass loss can also be observed at $\sim 600{ }^{\circ} \mathrm{C}$ for $\mathrm{NMC} \mathrm{BM}$, where the main transformation of $\mathrm{LiNi}_{0.33} \mathrm{Mn}_{0.33} \mathrm{Co}_{0.33} \mathrm{O}_{2}$ occurs. Moreover, as discussed, it seems that a significant part of the $\mathrm{C}$ in the $\mathrm{BM}$ is acetylene black, whose oxidation was detectable (because of its content) at $\sim 400{ }^{\circ} \mathrm{C}$ in the DTA graph. Therefore, it can be concluded that part of the transformation and reduction of the NMC cathode material begins at $\sim 400{ }^{\circ} \mathrm{C}$, where acetylene black acts as the reductant.

Section III, including the highest mass loss rate, begins immediately after phase transformation at $\sim 600{ }^{\circ} \mathrm{C}$. A bump between 700 and $800{ }^{\circ} \mathrm{C}$ is observed in the DTA curve, which is more obvious in the fine fraction (Fig. 10a). Similar to the discussion in the LCO BM section, it can be accounted for by the decomposition of $\mathrm{Li}_{2} \mathrm{CO}_{3}$ into $\mathrm{Li}_{2} \mathrm{O}$ and $\mathrm{CO}_{2}$. After reduction, the $\mathrm{Co} / \mathrm{Ni}$ phase forms, while part of the graphite remains unreacted. $\mathrm{MnO}$ and $\mathrm{SiO}_{2}$ remain in the sample, which agrees with the FactSage calculations (Fig. 13), and part of the $\mathrm{MnO}$ remains unreacted even at $1100{ }^{\circ} \mathrm{C}$. Moreover, there are LiF peaks that do not exist in the LCO XRD pattern. In Table 2, the F amounts are reported as 2.6 and $6.5 \mathrm{wt} \%$ in the LCO and NMC BM, respectively. Hence, the higher concentration of $\mathrm{F}$ in the NMC BM might lead to the formation of a detectable amount of $\mathrm{LiF}$ in the XRD pattern.

The experimental data obtained were compared to the FactSage modeling results (Fig. 13). FactSage shows that

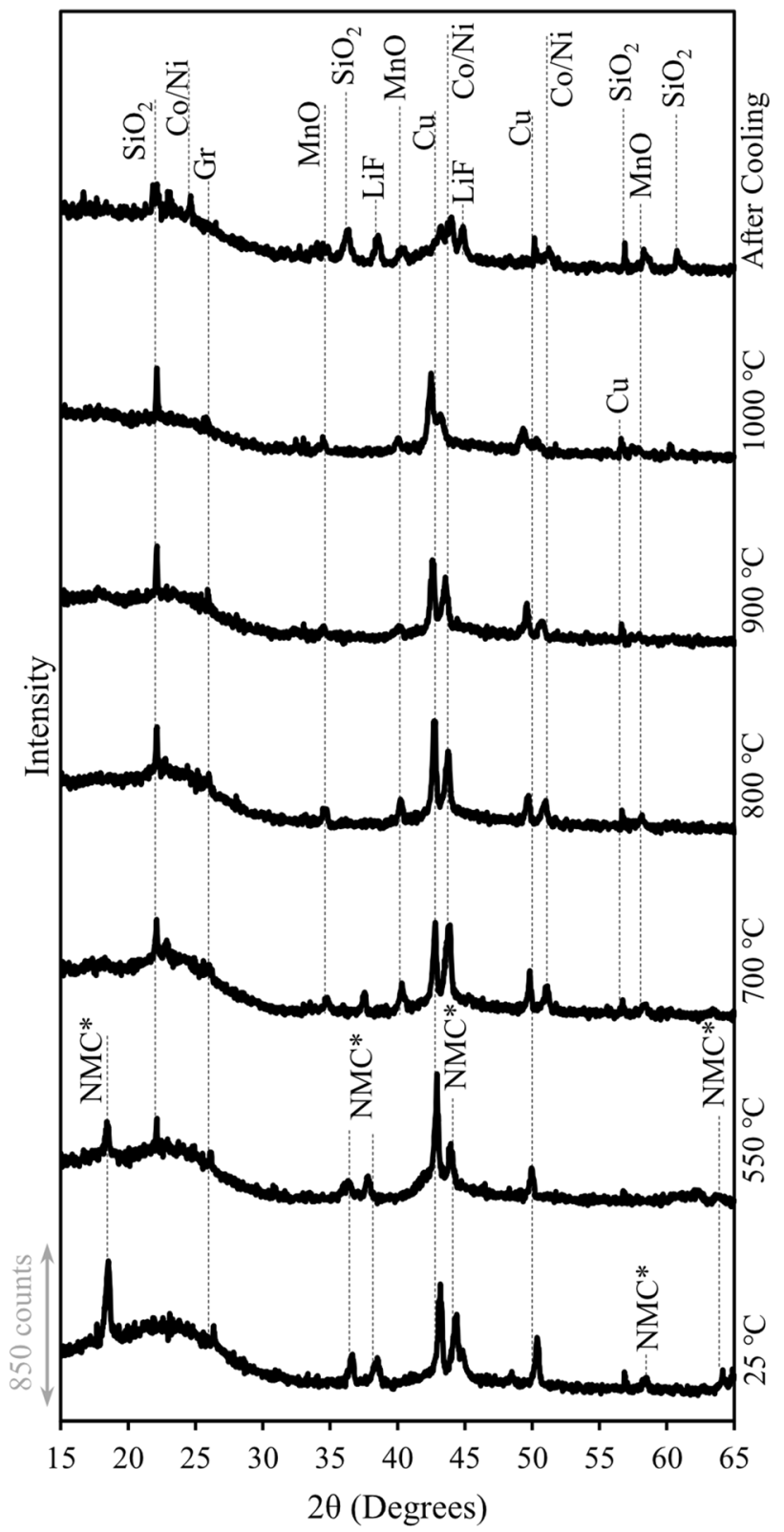

Fig. 12 XRD patterns during heating of the NMC BM to a temperature of $1000{ }^{\circ} \mathrm{C}$

a higher amount of $\mathrm{F}$ in NMC resulted in the formation of some fluorides-e.g., $\mathrm{LiF}, \mathrm{MnF}_{2}$, and $\mathrm{SiF}_{4}$. In the other words, the thermodynamic calculations demonstrated that $\mathrm{MnO}$ and $\mathrm{Li}_{2} \mathrm{O}$ partially react with $\mathrm{F}$ and form $\mathrm{Mn}$ and $\mathrm{Li}$ fluorides.

In the mass balance calculations, the reduction was assumed to be performed with $\mathrm{C}$ as the main reductant. In that regard, a $\mathrm{CO}: \mathrm{CO}_{2}$ ratio of 3:1 was selected as the composition of the produced gas, as previously explained. Since the total mass loss is the concern of this calculation, the formation of $\mathrm{Mn} / \mathrm{Li}$ fluorides are considered as reduced $\mathrm{Mn}$ 
and $\mathrm{Li}$ in the equations. Accordingly, three types of equations can be considered based on their products, as follows:

$$
\begin{aligned}
& \text { - } \mathrm{Co}, \mathrm{Ni}, \mathrm{Mn} \text {, and } \mathrm{Li} \text { (Eq. 3); } \\
& \text { - } \mathrm{Co}, \mathrm{Ni}, \mathrm{Mn} \text {, and } \mathrm{Li}_{2} \mathrm{O} \text { (Eq. 4); and } \\
& \text { - } \mathrm{Co}, \mathrm{Ni}, \mathrm{MnO} \text {, and } \mathrm{Li}_{2} \mathrm{O} \text { (Eq. 5). } \\
& \mathrm{LiNi}_{0.33} \mathrm{Mn}_{0.33} \mathrm{Co}_{0.33} \mathrm{O}_{2}+1.6 \mathrm{C} \rightarrow 0.33 \mathrm{Ni} \\
& +0.33 \mathrm{Mn}+0.33 \mathrm{Co}+\mathrm{Li}+1.2 \mathrm{CO}+0.4 \mathrm{CO}_{2} \\
& \mathrm{LiNi}_{0.33} \mathrm{Mn}_{0.33} \mathrm{Co}_{0.33} \mathrm{O}_{2}+1.2 \rightarrow 0.33 \mathrm{Ni}+0.33 \mathrm{Mn} \\
& +0.33 \mathrm{Co}+0.5 \mathrm{Li}_{2} \mathrm{O}+0.9 \mathrm{CO}+0.3 \mathrm{CO}_{2} \\
& \mathrm{LiNi}_{0.33} \mathrm{Mn}_{0.33} \mathrm{Co}_{0.33} \mathrm{O}_{2}+0.9 \mathrm{C} \rightarrow 0.33 \mathrm{Ni} \\
& +0.33 \mathrm{MnO}+0.33 \mathrm{Co}+0.5 \mathrm{Li}_{2} \mathrm{O}+0.7 \mathrm{CO}+0.2 \mathrm{CO}_{2}
\end{aligned}
$$

The experimental mass loss percentages were calculated after a temperature of $500{ }^{\circ} \mathrm{C}$ (PVDF decomposition) was reached and they were $20.4 \mathrm{wt} \%$ in the coarse fraction and $29.5 \mathrm{wt} \%$ in the fine fraction. The calculated mass loss percentages in Eqs. 3, 4, and 5 were $28.2 \mathrm{wt} \%, 21.1 \mathrm{wt} \%$, and $15.6 \mathrm{wt} \%$, respectively. Then, it can be speculated that in the coarse fraction, $\mathrm{Ni}$ and $\mathrm{Co}$ were fully reduced; however, $\mathrm{Li}$ and $\mathrm{Mn}$ oxides partially reacted with $\mathrm{F}$. Regarding the fine fraction, the high mass loss can be attributed to the late devolatilization of organic materials (binders).

\section{F Behavior}

NMC had a larger amount of F than LCO, and based on that, it was selected as the primary sample in this part of the

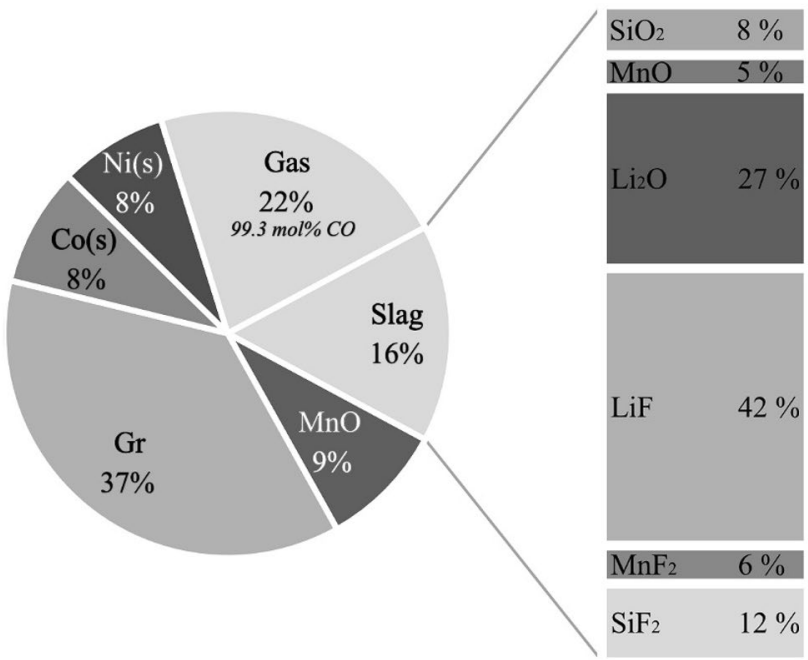

Fig. 13 NMC BM heat treated at $1100{ }^{\circ} \mathrm{C}$, calculated by FactSage: Phase distribution and the slag calculated components

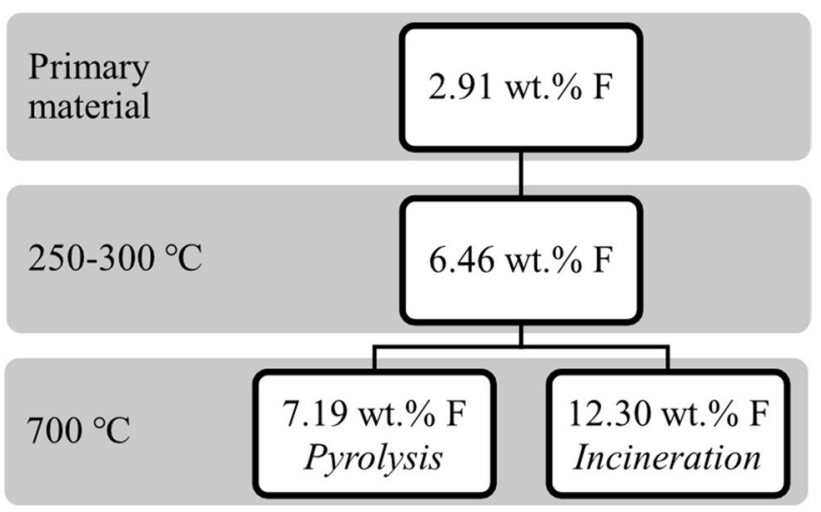

Fig. $14 \mathrm{~F}$ content after various heat treatment conditions

study. The $\mathrm{F}$ content after four different thermal treatments is listed in Fig. 14. The primary NMC BM had only $2.91 \mathrm{wt} \%$ $\mathrm{F}$, while it increased to $6.46 \mathrm{wt} \%$ by removal of electrolyte at 250-300 ${ }^{\circ} \mathrm{C}$. After pyrolysis at $700{ }^{\circ} \mathrm{C}$, there was $7.19 \mathrm{wt} \% \mathrm{~F}$ in the $\mathrm{BM}$, whereas it increased to $12.30 \mathrm{wt} \%$ after incineration at the same temperature.

As explained before, after transformation of the cathode material, $\mathrm{Li}_{2} \mathrm{CO}_{3}$ forms, decomposing into $\mathrm{Li}_{2} \mathrm{O}$ and $\mathrm{CO}_{2}$ at higher temperatures. The possible reactions that might occur with $F$ and the oxides can be summarized as Eqs. 6 and 7, as simulated by FactSage:

$2 \mathrm{Li}_{2} \mathrm{CO}_{3}+4 \mathrm{~F} \rightarrow 4 \mathrm{LiF}+2 \mathrm{CO}_{2}+\mathrm{O}_{2}$

$2 \mathrm{Li}_{2} \mathrm{O}+4 \mathrm{~F} \rightarrow 4 \mathrm{LiF}+\mathrm{O}_{2}$

The QMS results in Fig. 10 show that hydrocarbons $\left(\mathrm{C}_{x} \mathrm{H}_{y}\right)$ were released in section $\mathrm{I}-\mathrm{i}$.e., at temperatures lower than $500{ }^{\circ} \mathrm{C}$-which is a sign of PVDF decomposition in the BM. Comparing those data with the variation in $\mathrm{F}$ content in Fig. 14 indicates that heat treatment, even at $700{ }^{\circ} \mathrm{C}$, might produce hydrocarbons but does not remove $\mathrm{F}$ at that temperature. In addition, it seems that incineration results in a higher final $\mathrm{F}$ content than pyrolysis. It should be taken into account that in an oxidative atmosphere (incineration), graphite reacts with oxygen in the atmosphere and produces $\mathrm{CO} / \mathrm{CO}_{2}$. Thus, the $\mathrm{BM}$ mass loss in the air $(\sim 52 \mathrm{wt} \%)$ is higher than that in the Ar atmosphere ( $19 \mathrm{wt} \%)$. Normalizing the $\mathrm{F}$ content after heating at $700{ }^{\circ} \mathrm{C}$ based on the mass loss in both the pyrolysis and incineration processes demonstrates that the $\mathrm{F}$ amount removed from $100 \mathrm{~g}$ of $\mathrm{BM}$ are approximately 0.63 and $0.56 \mathrm{~g}$ in $\mathrm{Ar}$ and air atmospheres, respectively. This reveals that there might be some emission of $\mathrm{C}_{x} \mathrm{H}_{y}$, but it does not significantly affect the absolute $\mathrm{F}$ content.

The FactSage calculations, in line with the experimental results, show that $\mathrm{F}$ accumulated in the solid-state and did not evaporate in this range of working temperatures. It can 
Table 3 Calculated thermodynamic data regarding the F behavior at $700{ }^{\circ} \mathrm{C}$

\begin{tabular}{lccl}
\hline Heat treatment/atmosphere & $\begin{array}{l}\text { F content }(\mathrm{s}) \\
\text { Experimental }\end{array}$ & $\begin{array}{l}\text { F content }(\mathrm{s}) \\
\text { Calculated }\end{array}$ & $\begin{array}{l}\text { F-containing phases } \\
\text { Calculated }\end{array}$ \\
\hline Pyrolysis/Ar & 7.19 & 8.31 & $\mathrm{LiF}$ \\
Incineration/air & 12.30 & 13.21 & $\mathrm{LiF}, \mathrm{Li}_{2} \mathrm{SiO}_{3}(\mathrm{LiF})_{2}$ \\
\hline
\end{tabular}

be observed in Table 3 that the experimental and calculated data agree. Based on these thermodynamic calculations, $\mathrm{F}$ accumulates in the solid-state in the form of LiF after pyrolysis, and after incineration, $\mathrm{LiF}$ and $\mathrm{Li}_{2} \mathrm{SiO}_{3}(\mathrm{LiF})_{2}$ are supposed to form. According to thermodynamic modeling, $79 \%$ of $\mathrm{F}$ in the solid-state is in the form of $\mathrm{LiF}$, and the rest is in the $\mathrm{Li}_{2} \mathrm{SiO}_{3}(\mathrm{LiF})_{2}$ phase.

In this study, it was shown that regardless of the BM particle size, the morphological and mineralogical properties of the BM were almost the same. The main difference was in the amount of binders and graphite, which had a direct effect on the mass loss. The amounts of Li and F in the solidstate were also analyzed and tracked in the XRD measurements and the thermodynamic calculations. During thermal treatment of the BM, $600{ }^{\circ} \mathrm{C}$ was found to be a critical temperature for breaking the complex structure of the cathode material, which was followed by carbothermic reduction of the metallic oxides in the BM to obtain metallic $\mathrm{Co}$ and $\mathrm{Ni}$ (in the case of the NMC BM). Li was found in the form of $\mathrm{AlLiO}_{2}$ after heat treatment at a low concentration of $\mathrm{F}$, while the Li-containing phase changed to $\mathrm{LiF}$ at a high $\mathrm{F}$ content in the BM. F persisted in the BM, even after PVDF decomposition and the emission of hydrocarbons, regardless of whether the heat treatment was conducted in an inert or an oxidative atmosphere.

\section{Conclusion}

A characterization routine including the $\mathrm{BM}$ thermal behavior was investigated based on chemical, morphological, mineralogical, and thermal analyses. ICP seems to be the most appropriate tool to quantify the main elements in the BM, such as $\mathrm{Co}, \mathrm{Ni}, \mathrm{Mn}$, and $\mathrm{Li}$. The ISE method was found to be a reliable technique to quantify $\mathrm{F}$. The volatile content in the BM was determined utilizing TGA coupled with QMS. Although the total volatile content can be quantified, it was not possible to obtain detailed information on the volatile composition using the existing analytical tools. The presence of residual binder was identified in the SEM images, and its quantity along with acetylene black was further determined by TGA in the temperature range of $200-500{ }^{\circ} \mathrm{C}$. It was found that $5-10 \mathrm{wt} \%$ of the BM consisted of residual binders (mainly PVDF) and acetylene black. During thermal analysis, an exothermic peak at $\sim 600{ }^{\circ} \mathrm{C}$ in both $\mathrm{BM}$ types was attributed to the transformation of $\mathrm{LiCoO}_{2}$ and
$\mathrm{LiNi}_{0.33} \mathrm{Mn}_{0.33} \mathrm{Co}_{0.33} \mathrm{O}_{2}$ to their constituting metal oxides/ lower oxides. Transformation in both BM types was followed by the main mass loss, which indicated that reduction was possible only after the transformation of complex oxides to simpler oxides. The XRD results confirmed this observation at high temperatures. In the BM from NMC batteries, where $\mathrm{F}$ is higher in concentration than in the $\mathrm{BM}$ from $\mathrm{LCO}$ batteries, $\mathrm{LiF}$ formation was also observed. All observations were thermodynamically calculated and confirmed through FactSage software.

By following the $\mathrm{F}$ behavior during heating as a pretreatment and employing the ISE method for the analysis of $\mathrm{F}$ in the solid sample, it was proven that although hydrocarbons were emitted from binder decomposition, $\mathrm{F}$ remained in the sample even after heat treatment at $700{ }^{\circ} \mathrm{C}$ in both oxidative and inert atmospheres.

Based on this study, it can be stated that a considerable amount of graphite in the BM can be utilized as a reducing agent, and Co-based alloys can be successfully produced through simple pyrometallurgical treatment of BM. A study on the addition of external oxygen to the BM to efficiently utilize excess graphite will be performed later.

Acknowledgements This work was carried out with the support of the Swedish Energy Agency - the batterifonden program within the project "Resource-efficient recycling routes for discarded lithium ion batteries". The study is conducted within the context of CAMM ${ }^{2}$ (Center of Advanced Mining and Metallurgy) at Luleå University of Technology. The authors thank Britte-Louise Holmqvist and Dr. Aekjuthon Phounglamcheik for their experimental support.

Funding Open access funding provided by Lulea University of Technology.

\section{Declarations}

Conflict of interest On behalf of all authors, the corresponding author states that there is no conflict of interest.

Open Access This article is licensed under a Creative Commons Attribution 4.0 International License, which permits use, sharing, adaptation, distribution and reproduction in any medium or format, as long as you give appropriate credit to the original author(s) and the source, provide a link to the Creative Commons licence, and indicate if changes were made. The images or other third party material in this article are included in the article's Creative Commons licence, unless indicated otherwise in a credit line to the material. If material is not included in the article's Creative Commons licence and your intended use is not permitted by statutory regulation or exceeds the permitted use, you will need to obtain permission directly from the copyright holder. To view a copy of this licence, visit http://creativecommons.org/licenses/by/4.0/. 


\section{References}

1. Zhang W, Xu C, He W, Li G, Huang J (2018) A review on management of spent lithium ion batteries and strategy for resource recycling of all components from them. Waste Manag Res J Sustain Circ Econ 36:99-112. https://doi.org/10.1177/0734242X17744655

2. Zheng X, Zhu Z, Lin X, Zhang Y, He Y, Cao H, Sun Z (2018) A mini-review on metal recycling from spent lithium ion batteries. Engineering 4:361-370. https://doi.org/10.1016/j.eng.2018.05. 018

3. Ruismäki R, Rinne T, Dańczak A, Taskinen P, Serna-Guerrero R, Jokilaakso A (2020) Integrating flotation and pyrometallurgy for recovering graphite and valuable metals from battery scrap. Metals 10:680. https://doi.org/10.3390/met10050680

4. Makuza B, Tian Q, Guo X, Chattopadhyay K, Yu D (2021) Pyrometallurgical options for recycling spent lithium-ion batteries: a comprehensive review. J Power Sources 491:229622. https://doi. org/10.1016/j.jpowsour.2021.229622

5. European Commission (2020) Proposal for a REGULATION OF THE EUROPEAN PARLIAMENT AND OF THE COUNCIL concerning batteries and waste batteries, repealing Directive 2006/66/EC and amending Regulation (EU) No 2019/1020. https://eur-lex.europa.eu/legal-content/EN/TXT/?uri=CELEX\% 3A52020PC0798. Accessed 26 Aug 2021

6. Melin E (2019) State-of-the-art in reuse and recycling of lithiumion batteries-a research review. Circ. Energy Storage. http:// www.energimyndigheten.se/globalassets/forskning--innovation/ overgripande/state-of-the-art-in-reuse-and-recycling-of-lithiumion-batteries-2019.pdf. Accessed 4 Aug 2021

7. Boyden A, Soo VK, Doolan M (2016) The environmental impacts of recycling portable lithium-ion batteries. Procedia CIRP 48:188-193. https://doi.org/10.1016/j.procir.2016.03.100

8. Velázquez-Martínez O, Valio J, Santasalo-Aarnio A, Reuter M, Serna-Guerrero R (2019) A critical review of lithium-ion battery recycling processes from a circular economy perspective. Batteries 5:68. https://doi.org/10.3390/batteries5040068

9. Harper G, Sommerville R, Kendrick E, Driscoll L, Slater P, Stolkin R, Walton A, Christensen P, Heidrich O, Lambert S, Abbott A, Ryder K, Gaines L, Anderson P (2019) Recycling lithium-ion batteries from electric vehicles. Nature 575:75-86. https://doi.org/10.1038/s41586-019-1682-5

10. Mossali E, Picone N, Gentilini L, Rodrìguez O, Pérez JM, Colledani M (2020) Lithium-ion batteries towards circular economy: a literature review of opportunities and issues of recycling treatments. J Environ Manag 264:110500. https://doi.org/10. 1016/j.jenvman.2020.110500

11. Or T, Gourley SWD, Kaliyappan K, Yu A, Chen Z (2020) Recycling of mixed cathode lithium-ion batteries for electric vehicles: current status and future outlook. Carbon Energy 2:6-43. https:// doi.org/10.1002/cey2.29

12. Zhang G, He Y, Feng Y, Wang H, Zhu X (2018) Pyrolysis-ultrasonic-assisted flotation technology for recovering graphite and $\mathrm{LiCoO}_{2}$ from spent lithium-ion batteries. ACS Sustain Chem Eng 6:10896-10904. https://doi.org/10.1021/acssuschemeng.8b02186

13. Liu W, Zhong X, Han J, Qin W, Liu T, Zhao C, Chang Z (2019) Kinetic study and pyrolysis behaviors of spent $\mathrm{LiFePO}_{4}$ batteries. ACS Sustain Chem Eng 7:1289-1299. https://doi.org/10.1021/ acssuschemeng.8b04939

14. Vishvakarma S, Dhawan N (2019) Recovery of cobalt and lithium values from discarded Li-ion batteries. J Sustain Metall 5:204209. https://doi.org/10.1007/s40831-018-00208-4

15. Yu J, He Y, Ge Z, Li H, Xie W, Wang S (2018) A promising physical method for recovery of $\mathrm{LiCoO}_{2}$ and graphite from spent lithium-ion batteries: grinding flotation. Sep Purif Technol 190:45-52. https://doi.org/10.1016/j.seppur.2017.08.049
16. Kim S, Bang J, Yoo J, Shin Y, Bae J, Jeong J, Kim K, Dong P, Kwon K (2021) A comprehensive review on the pretreatment process in lithium-ion battery recycling. J Clean Prod 294:126329. https://doi.org/10.1016/j.jclepro.2021.126329

17. Brückner L, Frank J, Elwert T (2020) Industrial recycling of lithium-ion batteries - a critical review of metallurgical process routes. Metals 10:1107. https://doi.org/10.3390/met10081107

18. Chen X, Kang D, Li J, Zhou T, Ma H (2020) Gradient and facile extraction of valuable metals from spent lithium ion batteries for new cathode materials re-fabrication. J Hazard Mater 389:121887. https://doi.org/10.1016/j.jhazmat.2019.121887

19. Yang Y, Lei S, Song S, Sun W, Wang L (2020) Stepwise recycling of valuable metals from $\mathrm{Ni}$-rich cathode material of spent lithium-ion batteries. Waste Manag 102:131-138. https://doi.org/ 10.1016/j.wasman.2019.09.044

20. Jian Y, Zongliang Z, Gang Z, Liangxing J, Fangyang L, Ming J, Yanqing L (2021) Process study of chloride roasting and water leaching for the extraction of valuable metals from spent lithiumion batteries. Hydrometallurgy 203:105638. https://doi.org/10. 1016/j.hydromet.2021.105638

21. Wang W, Zhang Y, Liu X, Xu S (2019) A simplified process for recovery of $\mathrm{Li}$ and $\mathrm{Co}$ from spent $\mathrm{LiCoO}_{2}$ cathode using $\mathrm{Al}$ foil as the in situ reductant. ACS Sustain Chem Eng. https://doi.org/ 10.1021/acssuschemeng.9b01564

22. Lombardo G, Ebin B, St Foreman MRJ, Steenari BM, Petranikova M (2019) Chemical transformations in Li-ion battery electrode materials by carbothermic reduction. ACS Sustain Chem Eng 7:13668-13679. https://doi.org/10.1021/acssuschemeng.8b06540

23. Lombardo G, Ebin B, Foreman MR, Steenari BM, Petranikova M (2020) Incineration of EV Lithium-ion batteries as a pretreatment for recycling - determination of the potential formation of hazardous by-products and effects on metal compounds. J Hazard Mater 393:122372. https://doi.org/10.1016/j.jhazmat.2020.122372

24. Kwon OS, Sohn I (2020) Fundamental thermokinetic study of a sustainable lithium-ion battery pyrometallurgical recycling process. Resour Conserv Recycl 158:104809. https://doi.org/10. 1016/j.resconrec.2020.104809

25. Bale CW, Bélisle E, Chartrand P, Decterov SA, Eriksson G, Gheribi AE, Hack K, Jung IH, Kang YB, Melançon J, Pelton AD, Petersen S, Robelin C, Sangster J, Spencer P, Van E-A (2016) FactSage thermochemical software and databases-2010-2016. Calphad 54:35-53

26. Nitta N, Wu F, Lee JT, Yushin G (2015) Li-ion battery materials: present and future. Mater Today 18:252-264. https://doi.org/10. 1016/j.mattod.2014.10.040

27. Hallam KR, Darnbrough JE, Paraskevoulakos C, Heard PJ, Marrow TJ, Flewitt PEJ (2021) Measurements by X-ray diffraction of the temperature dependence of lattice parameter and crystallite size for isostatically-pressed graphite. Carbon Trends 4:100071. https://doi.org/10.1016/j.cartre.2021.100071

28. Suryanarayana C, Norton MG (1998) X-ray diffraction: a practical approach. Springer, New York

29. An L (2019) Recycling of spent lithium-ion batteries. Springer, Cham

30. Ross BJ, LeResche M, Liu D, Durham JL, Dahl EU, Lipson AL (2020) Mitigating the impact of thermal binder removal for direct Li-ion battery recycling. ACS Sustain Chem Eng 8:12511-12515. https://doi.org/10.1021/acssuschemeng.0c03424

31. Hanisch C, Loellhoeffel T, Diekmann J, Markley KJ, Haselrieder W, Kwade A (2015) Recycling of lithium-ion batteries: a novel method to separate coating and foil of electrodes. J Clean Prod 108:301-311. https://doi.org/10.1016/j.jclepro.2015.08.026

32. Yang Y, Huang G, Xu S, He Y, Liu X (2016) Thermal treatment process for the recovery of valuable metals from spent lithiumion batteries. Hydrometallurgy 165:390-396. https://doi.org/10. 1016/j.hydromet.2015.09.025 
33. Ahmed H, Sideris D, Björkman B (2020) Injection of $\mathrm{H}_{2}$-rich carbonaceous materials into the blast furnace: devolatilization, gasification and combustion characteristics and effect of increased $\mathrm{H}_{2}-\mathrm{H}_{2} \mathrm{O}$ on iron ore pellets reducibility. J Mater Res Technol 9:16029-16037. https://doi.org/10.1016/j.jmrt.2020.11.042

34. Kuzuhara S, Ota M, Tsugita F, Kasuya R (2020) Recovering lithium from the cathode active material in lithium-ion batteries via thermal decomposition. Metals 10:1-13. https://doi.org/10.3390/ met10040433

35. Kim JW, Lee HG (2001) Thermal and carbothermic decomposition of $\mathrm{Na}_{2} \mathrm{CO}_{3}$ and $\mathrm{Li}_{2} \mathrm{CO}_{3}$. Metall Mater Trans B Process
Metall Mater Process Sci 32:17-24. https://doi.org/10.1007/ s11663-001-0003-0

36. Yang L, Yang L, Xu G, Feng Q, Li Y, Zhao E, Ma J, Fan S, Li $X$ (2019) Separation and recovery of carbon powder in anodes from spent lithium-ion batteries to synthesize graphene. Sci Rep 9:9823. https://doi.org/10.1038/s41598-019-46393-4

Publisher's Note Springer Nature remains neutral with regard to jurisdictional claims in published maps and institutional affiliations. 